\title{
The Combined Effect of the Initial Cure and the Type of Cement on the Natural Carbonation, the Portlandite Content, and Nonevaporable Water in Blended Cement
}

\author{
Saida Boualleg, ${ }^{1}$ Mohamed Bencheikh, ${ }^{1}$ Larbi Belagraa, ${ }^{2}$ \\ Aziz Daoudi, ${ }^{3}$ and Mohamed Aziz Chikouche ${ }^{4}$ \\ ${ }^{1}$ Geo Materials Development Laboratory, Technology Faculty, Department of Civil Engineering, M'sila University, \\ P.O. Box 166, Ichbilia, 28000 Msila, Algeria \\ ${ }^{2}$ Materials and Electronic Systems Laboratory (LMSE), Faculty of Science and Technology, \\ Bachir El Ibrahimi University of Bordj Bou Arréridj, 34260 Bordj Bou Arréridj, Algeria \\ ${ }^{3}$ Research Center \& Technology Services Industry Building Materials, CETIM, P.O. Box 7, Cité Ibn Khaldoun, \\ 35000 Boumerdès, Algeria \\ ${ }^{4}$ Materials and Mechanics of Structures Laboratory (LMMS), Technology Faculty, Department of Civil Engineering, \\ M'sila University, P.O. Box 166, Ichbilia, 28000 M'sila, Algeria
}

Correspondence should be addressed to Saida Boualleg; sabah_bou@yahoo.fr

Received 20 January 2017; Accepted 28 February 2017; Published 29 March 2017

Academic Editor: Xiao-Yong Wang

Copyright (C) 2017 Saida Boualleg et al. This is an open access article distributed under the Creative Commons Attribution License, which permits unrestricted use, distribution, and reproduction in any medium, provided the original work is properly cited.

The aim of this work is to better understand the physical and chemical phenomena involved in hydrated mix (clinker + addition) during the natural carbonation process, to characterize cement with supplementary cementitious materials (SCMs) under various curing environment. The prepared cement pastes were characterized by thermogravimetric analysis. The results showed a considerable influence of the environment on the properties of mortars and cement and a perfect correlation between compressive strength, natural carbonation, nonevaporable water, and portlandite content. It was observed that the reduction of the curing period makes the mortars more sensitive. The kinetics of process was evaluated from $\mathrm{Ca}(\mathrm{OH})_{2}$ content and nonevaporable water contained in mortars. These two parameters reflect the hydration progress of the water/cement ratio studied. The weight loss due to $\mathrm{Ca}(\mathrm{OH})_{2}$ decomposition, calculated by DTA/TG analysis, shows the effect of the pozzolanic reaction and the natural carbonation. The supplementary cementitious materials (SCMs) play a considerable role in the slowing down of the aggression environment.

\section{Introduction}

Obviously, there is a close link between $\mathrm{CO}_{2}$ concentrations in atmosphere and materials, especially the cementitious materials, making them able to be carbonated. The carbonation depth is evidently higher with a great level of $\mathrm{CO}_{2}$. The carbonation rate depends on the infiltration of carbon dioxide into the cement matrix. The interior humidity and environment exposure of cement matrix determine saturation level and $\mathrm{CO}_{2}$ transfer. So the presence of humidity source is primordial [1].

The carbonation effect consists in the action of atmosphere especially $\mathrm{CO}_{2}$ gas. It is diffused into concrete voids and dissolves to acid. This medium changes lead to the dissolution of hydrates especially the portlandite. The carbonation effect rate depends on many parameters; we mainly focused on two of them, the porosity and the portlandite content. Indeed, the portlandite content is a key parameter if we are interested in the carbonation and its buffering effect on the interstitial $\mathrm{pH}$ solution through a hydroxide ion on dissolution release. This solution is also accompanied by a release of calcium ions $\mathrm{Ca}^{+2}$, which are able to react with the carbonate ions $\mathrm{CO}_{3}{ }^{-2}$, forming the calcium carbonate $\mathrm{CaCO}_{3}$ $[2,3]$.

The supplementary cementitious materials (SCM) in blended cement have a pozzolanic or hydraulic characters; 
they can modify the cement hydration and also contribute with cementitious products to the matrix structure [4].

The ordinary Portland cement (OPC) is more resistant to carbonation than blended cement with pozzolanic additions, if the different buffering effects of their hydrated phases and alkali contents are considered. In the absence of carbonation or any other attack $[5,6]$, which causes a $\mathrm{pH}$ vanishing, this can reach values nearly 14.1 in the pore solution of an OPC. When the mechanism of carbonation is dissolution (in the case of OPC), during the attack, the portlandite solubility maintains the $\mathrm{pH}$ level at 12.5 .

Several studies [7-9] have discussed the carbonation process in conventional materials (concrete and mortar) using different methods of investigation such as spraying phenolphthalein; the main objective of these studies was the determination of the carbonation front. Differential thermal analysis (DTA) combined with thermogravimetric analysis (TGA) is more suitable for studying hydration at later stages. This technique has been applied to quantify the portlandite in cement/silica fume, metakaolin, fly ash, blast furnace slag, and calcined clay system [10-13]. They also reported how the portlandite of pozzolanic addition contributes to the hydration reaction of cement $[14,15]$. Essentially, the investigations focused on the determination of the reactivity of different pozzolans.

Portlandite content of cementitious materials is a durability and performance indicator of concrete structures against carbonation because the portlandite represents the basicity reserve of cementitious materials; it maintains a high $\mathrm{pH}$ of $12.6[16]$.

The main objective of studies is the determination of the carbonation front to prevent corrosion of steel in reinforced concrete. The kinetics of carbonation is influenced by the amount of corrosion products [17].

When clinker is substituted by some SCMs, portlandite content decreases and concrete became sensitive to carbon dioxide presence. The mechanical strength is closely related to the portlandite content. In carbon dioxide diffusion process, relative humidity plays an important role because the diffusion coefficient of carbon dioxide in the air is ten thousand times higher than in water [18].

A higher $\mathrm{pH}$ level (12.4) protects steel from corrosion. In front of the great diversity of hydraulic SCMs used today, the data like mechanical strength, W/C ratio, or cement content are insufficient to translate complexity of the cementitious materials. For example, some SCMs, such as the mineral additions, consume a party of portlandite through chemical reactions as the case of pozzolanic reactions. For these additions, they reduce porosity of cementitious materials and a good mechanical strength is reached, on account of high particles fineness which plays the role of fillers to fill the voids like silica fume. Thus, from chemical point of view these new materials may be durable due to a low portlandite content; from physical point of view they constitute an effective obstacle to $\mathrm{CO}_{2}$ penetration.

A compromise could be found to properly formulate these cementitious materials and ensure their durability. Calculating the portlandite content as a chemical indicator, porosity, and permeability like physical indicators allows solving this kind of problematic situation [19].

The necessity for curing time and conditions occurs from the fact that cement hydration takes place only in water filled capillaries. So, in order to obtain a good mortar or concrete, the setup of an appropriate mix must be followed by the curing in appropriate environment during the early ages of hardening and water loss capillaries by evaporation must be prevented [20, 21].

Taking into consideration the action of carbon dioxide, the curing period is a determining factor in the behavior of cement. If the conditions and curing time are sufficient, slag and pozzolanic cement have a good carbonation resistance [22]. The curing conditions, particularly treatment period, affect concrete durability against carbonation [23].

It is necessary that the relative humidity of the storage medium is greater than $80 \%$, so that the cement hydration process continues. The convenient curing of concrete facilitates the cement hydration which leads to improve mechanical properties of concrete. Extended wet cure period of concrete causes a decrease of carbonation concrete depth [23, 24]; ACI 308 (recommended practice) suggests 7 days of wet cure for most structural concrete [25].

However, the curing period should be extended to 14 days when the cement contains SCMs, such as slag and fly ash, due to the slow hydration reactions between them and the calcium hydroxide. This reaction requires the presence of water to produce the cement hydrates and contributes to filling the capillary voids.

Sajedi and Razak shows that the effect of the first week of underwater cure of OPC $50 \mathrm{~mm}$ mortar cubes after mixing is equal to or even more than 12 weeks of underwater cure after the first week of mixing [26]. Other studies have shown that initial underwater curing is very important in improving mechanical properties of concrete. It shows that the initial 4 days of curing was sufficient to develop compression strength higher than the compression strength at 28 and 90 days of continuous underwater curing [27].

Aitcin et al. recorded the difference of compression strength at the order of $17 \%$ to $22 \%$ between concrete samples that are stored in air and wet [28]. Shafiq and Cabrera shows that the concrete made with ordinary Portland cement (OPC) and left in the air had a porosity of $5 \%$ to $10 \%$ higher than the wet concrete samples at 28 days [29]. A good correlation was observed between the coefficients of sorptivity and the compression strength of concrete; the latter factor increased due to hydration, but the sorptivity decreased significantly indicating a denser microstructure [30]. The uses of mineral additions modify chemical equilibrium of concrete and can affect $\mathrm{pH}$ of pore solution. The linear model proposed by Balayssac et al. independent of cement type, the dosage, and curing time registered a regression coefficient $\left(R^{2}=0.92\right)$ which is quite acceptable [31].

For a given cement content, carbonation is more important for a concrete CEM II/B (20\% of limestone fillers) than for a CEM I concrete. For a cement content of $250 \mathrm{Kg} / \mathrm{m}^{3}$, the carbonation depth for CEM II/B-based concrete is about $30 \%$ 
TABLE 1: Composition of the different mixtures [33].

\begin{tabular}{lccccccc}
\hline Mixtures & Clinker [\%] & Gypsum [\%] & Slag [\%] & Pozzolana [\%] & Additions secondary [\%] & Design mixtures & NF EN197-1 \\
\hline CPA $^{*}$ & 95 & 0 & 0 & 0 & 0 & Control cement & CEMI52.5 \\
CRS $^{* *}$ & 88 & 5 & 0 & 0 & 7 & Binary cement & CEMII42.5 \\
CL30\% $^{\$}$ & 65 & 5 & 30 & 0 & 0 & Binary cement & CEMII/B-S32.5 \\
CZ30\% $^{\$ \varsigma}$ & 65 & 5 & 0 & 30 & 0 & Binary cement & CEMII/B-P32.5 \\
\hline
\end{tabular}

Blended cement (cement based added) $=$ addition/clinker $(\%)$.

$\mathrm{CPA}^{*}$ : artificial Portland cement $=0 /$ clinker $=0 / 100$.

CRS $^{* *}$ : sulphate resistant cement (secondary addition) AS/clinker $=07 / 93$.

CL30\% ${ }^{\S}$ : cement with slag addition $=\mathrm{L} /$ clinker $=30 / 70$.

$\mathrm{CZ30 \%}{ }^{\S \$}$ : cement with pozzolana addition $=\mathrm{PZ} /$ clinker $=30 / 70$.

higher than CEM I-based concrete, whatever the curing time. Therefore, the carbonation depth is related to clinker dosage [31].

In this study, we are interested specifically to the relation between wet cure and mechanical and chemical properties of mortars and cement. Four types of cement were prepared (clinker effect is taken into account in the preparation of cement with the various SCMs), plus artificial Portland cement (CEMI) as a reference. The TG analysis quantifies the carbon dioxide fixed to each type of hydrate (CSH) in different medium and at different time. Nonevaporable water was used to determine the hydration degree of cement.

\section{Experimental Program}

\subsection{Materials}

2.1.1. Cement. Four cement types from the same clinker were prepared; we have characterized as completely as possible a compound cement (CPL30\%-CEMII/B-S) class $32.5 \mathrm{MPa}$ with $30 \%$ of slag and a (CPZ30\%-CEMII/B-P) class $32.5 \mathrm{MPa}$ with $30 \%$ of pozzolana, to be compared to (PC-CEMI) $52,5 \mathrm{MPa}$ (Portland cement PC) and a (CRS-CEMII) class $42.5 \mathrm{MPa}$ with secondary additions (cement sulphate resis$\operatorname{tant);~this~is~to~better~locate~the~slag~cement~and~pozzolanic~}$ blended cement.

Algerian local products (clinker, gypsum, slag, and pozzolana) were crushed to a particle size less than $1 \mathrm{~mm}$ before being thoroughly mixed. Because of the hardness, strength, and abrasion of the clinker the separate grinding of raw materials was adopted, which consequently improves the physical and thermal characteristics of modified cement and enhance the properties of these materials [32].

The dosage of natural gypsum was kept constant at $5 \%$ for two reasons, first to regulate setting time and secondly to not hide the effect of addition on the mechanical properties of cement. These were divided and prepared to the proportions given in Table 1 Their chemical composition was determined by X-ray fluorescence in Table 2 [33]. The mineralogical composition of the cement according to the Bogue formulation and physical characteristics are presented in Table $3[33,34]$.

2.1.2. Sand. The standard sand CEN (ISO standard sand) is clean natural siliceous sand including its fine fractions with the grains generally rounded and isometric. It was dried, screened, and prepared in a modern workshop with a required quality and coherence according to the certified standard CEN EN 196-1, ISO Standard Sand, and ISO 679: 2009 [35].

2.1.3. Water. The water is drinking quality water in regard to the requirements of standard NF P 18-404.

2.2. Test Procedures and Specimens. All normalized mortars were prepared by mixing $1350 \mathrm{~g}$ of normalized sand, $450 \mathrm{~g}$ of cement, and $225 \mathrm{~g}$ of water. These samples were demolded after $24 \mathrm{~h}$ and placed in water bath maintained at $23^{\circ} \mathrm{C}$. Compressive tests were carried out on mortars at different ages according to EN 196-1 [36].

Reference samples were kept in air-conditioned room $\left(\mathrm{RH}=65 \%, T=20^{\circ} \mathrm{C}\right)$. The initial wet cure was considered for $(3,7,28)$ days in wet room $\left(\mathrm{RH}=95 \%, T=20^{\circ} \mathrm{C}\right)$ and then stored in air-conditioned room $\left(\mathrm{RH}=65 \%, T=20^{\circ} \mathrm{C}\right)$ for 1 year [31].

To assess compressive strength six samples were tested. Size of samples for pure paste was cylindrical $(2.5 / 5.5 \mathrm{~cm})$ and prepared and conserved in such conditions in humid room $\left(T=20^{\circ} \mathrm{C}, \mathrm{RH}=95 \%\right)$.

2.2.1. Compressive Strength Test. The tests were performed according to standard NF EN 196-1. The half-prisms were taken to a compressive machine to assess the compressive strength. The resistance is calculated using the formula: compressive strength $=$ load $\left(F_{c}\right) /$ cross-sectional area $(S)$ for four types of mortars $\left(4 \times 4 \times 16 \mathrm{~cm}^{3}\right)$ at the age of testing after one year.

2.2.2. Carbonation Test Method. Natural carbonation in airconditioned room $\left(T=20^{\circ} \mathrm{C}, \mathrm{HR}=65 \%\right)$ was determined by the phenolphthalein method, in which the samples are divided into two and the broken surface is sprayed with phenolphthalein indicator. The indicator makes the mortar turn a reddish purple color (the healthy cement reflects the basic medium $\mathrm{pH}=14$ ). Carbonation depth is the distance between the external surface of the mortar and the end of the colored region. The result of carbonation depth corresponds to the thickness with no change of color, while the remaining area (with change of color) indicates $\mathrm{pH}>9$. This method slightly underestimates the carbonation depth since the reaction occurs for a $\mathrm{pH}<10-11$ [37]. Measurements are made for each mortar once a year. 
TABLE 2: Chemical composition of cement used (\%) [33].

\begin{tabular}{lccccccccccc}
\hline Cement & $\mathrm{CaO}$ & $\mathrm{SiO}_{2}$ & $\mathrm{Al}_{2} \mathrm{O}$ & $\mathrm{Fe}_{2} \mathrm{O}_{3}$ & $\mathrm{MgO}$ & $\mathrm{TiO}_{2}$ & $\mathrm{Na}_{2} \mathrm{O}$ & $\mathrm{K}_{2} \mathrm{O}$ & $\mathrm{P}_{2} \mathrm{O}_{5}$ & $\mathrm{SO}_{3}$ & $\mathrm{~L} . \mathrm{O} . \mathrm{L}$ \\
\hline CEM I & 64.24 & 20.25 & 5.13 & 3.73 & 1.69 & 0.26 & 0.16 & 0.62 & 0.11 & 2.28 & 1.53 \\
CEMII & 63.29 & 21.18 & 4.37 & 4.77 & 1.46 & 0.19 & 0.12 & 0.29 & 0.17 & 1.14 & 3.02 \\
CEMII/B-S & 44.4 & 36.1 & 4.73 & 4.57 & 2.3 & 0.29 & 0.49 & 0.16 & 1.98 & 2.19 & 3.06 \\
CEMII/B-P & 43.66 & 35.25 & 8.42 & 3.67 & 1.5 & 0.34 & 1.01 & 1.65 & 0.13 & 2.41 & 1.96 \\
\hline
\end{tabular}

TABLE 3: Mineralogical composition (\%) and physical characteristics [33, 34].

\begin{tabular}{lccccc}
\hline Cement type & $\begin{array}{c}\text { Blaine specific } \\
\text { surface }\left(\mathrm{cm}^{2} / \mathrm{g}\right)\end{array}$ & $\begin{array}{c}\text { Specific density } \\
\left(\mathrm{g} / \mathrm{cm}^{3}\right)\end{array}$ & $\mathrm{C}_{3} \mathrm{~S}$ & $\mathrm{C}_{2} \mathrm{~S}$ & $\mathrm{C}_{3} \mathrm{~A}$ \\
\hline CEM I & 3420 & 3.15 & 59 & 13 & 07 \\
CEMII & 3210 & 3.18 & 54 & 20 & 11 \\
CEMII/B-P & 3750 & 3.1 & 57 & 17 & 04 \\
CEMII/B-S & 3210 & 3.12 & 59 & 17 & 07 \\
\hline
\end{tabular}

2.2.3. TG and DTA Measurements. The thermal gravimetric (TG) analysis measures the difference of masses between a reference and specimen sample. The differential thermal analysis (DTA) records the difference of temperature with thermocouple located under the nacelles. These two analyses have been recorded using Netzsch STA 409 machine. Tests were carried out from $20^{\circ} \mathrm{C}$ up to $800^{\circ} \mathrm{C}$ under reconstituted air $\left(80 \% \mathrm{~N}_{2}\right.$ and $\left.20 \% \mathrm{O}_{2}\right)$ with a constant heating rate $\left(10^{\circ} \mathrm{C} / \mathrm{min}\right)$ in alumina crucible.

\section{Results and Discussion}

3.1. Effect of the Initial Cure on the Compressive Strength. Figure 1 shows the relationship between the compressive strength and the type of cement for a wet cure $\left(T=20^{\circ} \mathrm{C}, \mathrm{RH}\right.$ $=95 \%)$ and the air cure $\left(T=20^{\circ} \mathrm{C}, \mathrm{RH}=65 \%\right)$ for one year.

These curves shows that, on the one hand, the compound cement has a different kinetics of CPA (CEMI) and the CRS (CEMII) and slow kinetics in the long term and the resistance class for composite cement is much lower than those of the CPAs and CRS. This is explained by the low content of clinker in cement which considerably lowers down their hydration especially at young age. This is in agreement with the results of previous research works $[38,39]$. The slowness of the reaction for the hydration process is attributed to the mineral additions $[40,41]$.

The specimens left exposed to air presented the lowest resistance. However, those undergoing a curing regime gave the best results. An approximate explanation is that in the test pieces having been left untreated for one year a large part of their mixing water is evaporated. As a result, the hydration of the cement and the development of resistance have been stopped. Moreover, conservation in the laboratory conditions favors the development of microcracks inside the test pieces, which resulted in the decrease of the resistances after one year of age.

At one year the difference between the resistances of the treated and untreated specimens increased considerably. Indeed, for a CPA mortar, an increase in the cure duration of 3 days relative to the control mortar increases the strength of

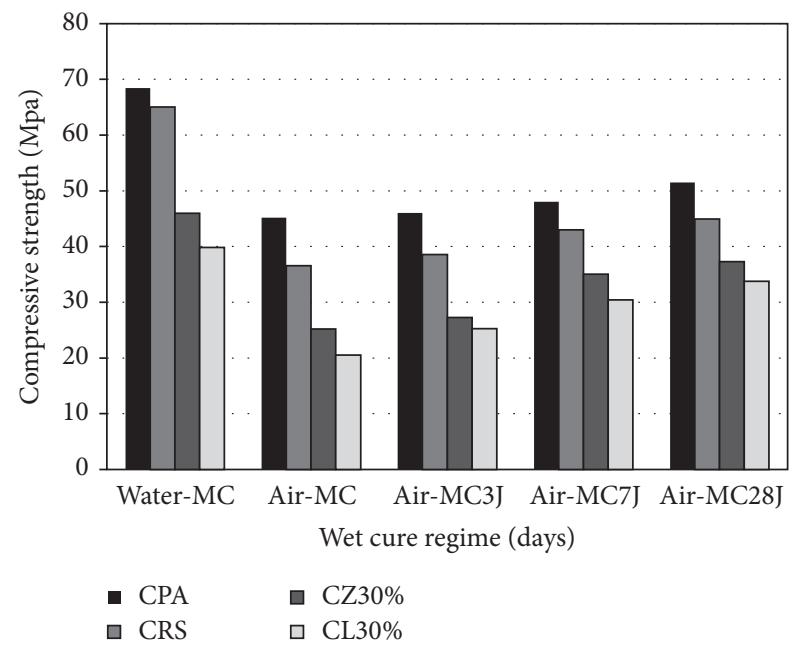

FIGURE 1: Effect of wet curing time on the mechanical performance.

$2 \%, 6.4 \%$ (7 days of treatment/control), and 14\% (28 days of treatment/control). For a CRS mortar a longer curing time of 3 days compared to the control mortar increases the mechanical strength by $5.6 \%$ which is $17.61 \%$ (7 days of cure/control) and $23 \%$ (28 days of cure/control), respectively. For the mortar $\mathrm{CZ30} \%$ the three-day cure time duration relative to the control mortar increases the mechanical strength by about $8.2 \%, 39 \%$ (7 days of cure/control), and 48\% (28 days of cure/control), respectively. For the mortar CL30\% the threeday cure time with respect to the control mortar increases mechanical strength of $23.05 \%, 48.1 \%$ (7 days of treatment/control), and $64.15 \%$ (28 days of treatment/control), respectively.

Indeed, underwater maturation promotes hydration, especially to the skin of surface of the samples, which progressively increases their compactness because hydration consumes the internal water causing the reduction of its content and the solidification of the concrete. The underwater cure promotes the formation of the hydrates leading to the filling of the pores by means of a continuous supply of water, leading 
CPA

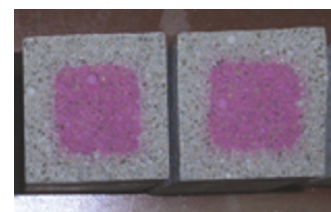

CZ30\%

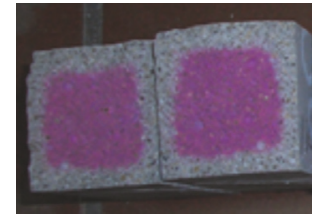

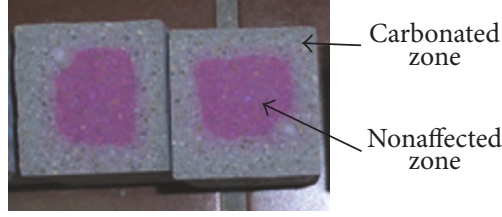

CRS

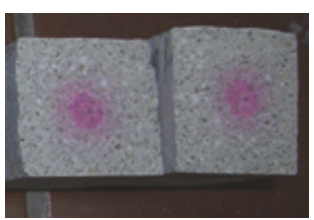

CL30\%
FIGURE 2: Continuous air cure for one year.

to the improvement of the porosity. While in the case of the "air" conservation control, the upper part is rapidly dried, which slows down the hydration and leads to low compressive strengths [42-44]. The strength is less important for composite cement than CPA and CRS. This is explained by the fact that compound cement contains 70 clinkers versus $100 \%$ for CPA cement and CRS only. This fact results in a lower amount of hydrates with higher resistance [31, 40, 41].

A good continuous cure at a relative humidity is still favorable to a better hydration in cement [45]; the wet cure increases the specific resistance $[42,46]$ as similar work undertaken for the case of the studied cement.

\subsection{Carbonation}

3.2.1. Detection by Phenolphthalein. The most widely used technique for quantifying the carbonation kinetics is the detection of a limit below which the $\mathrm{pH}$ is around 9, which is called the carbonation front detected by the colored turn of the phenolphthalein. The latter is spread on a freshly split sample; the noncarbonated part is colored pink while the carbonated part remains colorless.

Natural carbonation was in an air-conditioned room $(T=$ $20^{\circ} \mathrm{C}, \mathrm{RH}=65 \%$ ), for one year on mortars mixtures of CPA, CRS, CZ30\%, and CL30\%.

3.2.2. The Natural Carbonation Depth. Figure 2 shows the carbonation of the control mortar for a continuous cure in air is greater than that which has undergone the wet cure. In contrast to storage in open air, water vapor maturation promotes hydration and thus leads to a less porous mortar and thus has the least carbonation of the affected products [47-49]. This is due to rapid drying which considerably affects the performance of mortars exposed to carbonation, whatever the nature of the binder.

During air conservation of samples, the superficial part dries quickly, which slows the hydration and leads to a greater depth of carbonation. CL30\% mortar affected by a high carbonation depth, insufficient wet cure, clinker substitution by slag, and the amount of $\mathrm{Ca}(\mathrm{OH})_{2}$ will be reduced in part by the low amount of Portland cement and on the other hand by the pozzolanic reaction (consumption of the portlandite).

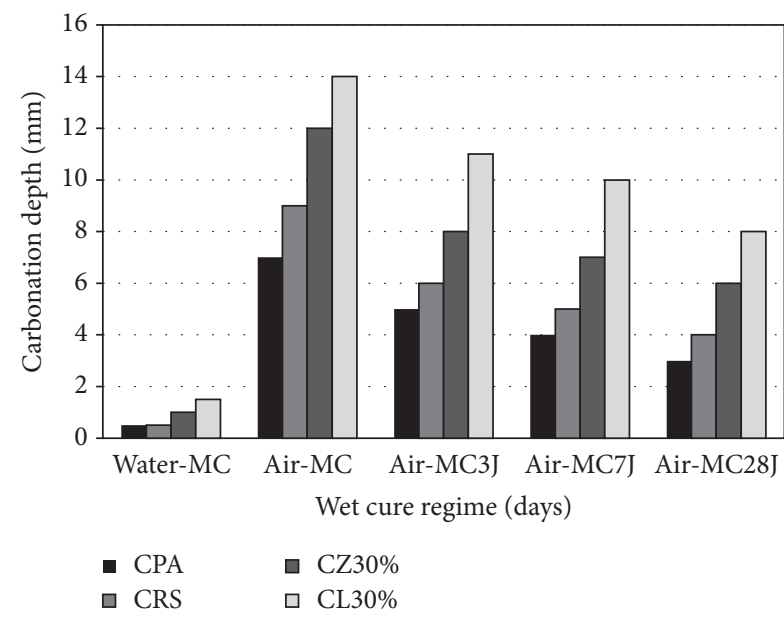

FIGURE 3: Influence of wet curing regime on the carbonation attitude of cement at one year.

Therefore, the introduction of the natural additions in mortars leads to a low portlandite $\mathrm{Ca}(\mathrm{OH})_{2}$ content. As a result, a smaller amount of $\mathrm{CO}_{2}$ is needed to react with calcium to consume the whole of portlandite, so that the $\mathrm{pH}$ falls more easily [50]. The effect of substitution by clinker is the pozzolanic reaction that consumes portlandite to form hydrated calcium silicates. Such cement may be more sensitive to the presence of carbon dioxide [51].

3.3. Effect of Initial Cure on the Carbonation Depth. Figure 3 shows the relationship between the carbonation and the type of cement at the age of one year. Naturally, the most carbonated cement is that made with the lowest clinker dosages.

The duration of wet curing significantly decreases the carbonate depth, especially when the clinker dosage is lower.

The dosage of the clinker decreases and makes higher kinetics of carbonation. This is directly attributed to the role played by the porosity of cementitious matrix. Indeed, the more the clinker of lower dosage, the more the porosity, leaving voids that favor, on the one hand, the movement of the free water located more deeply in the mortar and on the other hand the penetration and the diffusion of the carbon dioxide [52].

In fact, for an increase in the curing time of 3 days, it is possible to decrease the carbonate depth by nearly $20 \%$ for a CPA cement by comparing the control to the air at one year with a registered decrease of $43 \%$ and $57 \%$ for 7 days of cure/ control in air and 28 days of cure/control in the air, respectively.

For CRS cement, we registered a reduction rate of $33 \%$ at 3 days, $44 \%$ at 7 days, and $55 \%$ at 28 days of cure against control specimen in a simple air curing. For CZ30\%, we noted $33 \%$ of reduction at 3 days, $42 \%$ at 7 days, and $50 \%$ at 28 days. The mortar with CL30\% cement marked $21 \%$ of reduction at 3 days, $29 \%$ at 7 days, and $43 \%$ at 28 days.

This reduction is caused by lime content of clinker. More lime in cement induced lower carbonation. Slug and pozzolan cement contain less of portlandite than CPA and CRS ones. 


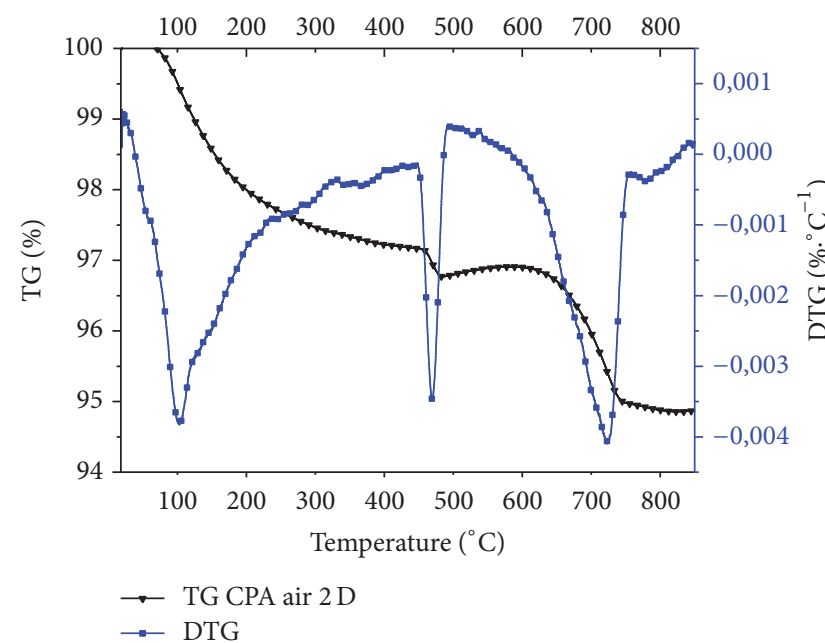

(a)

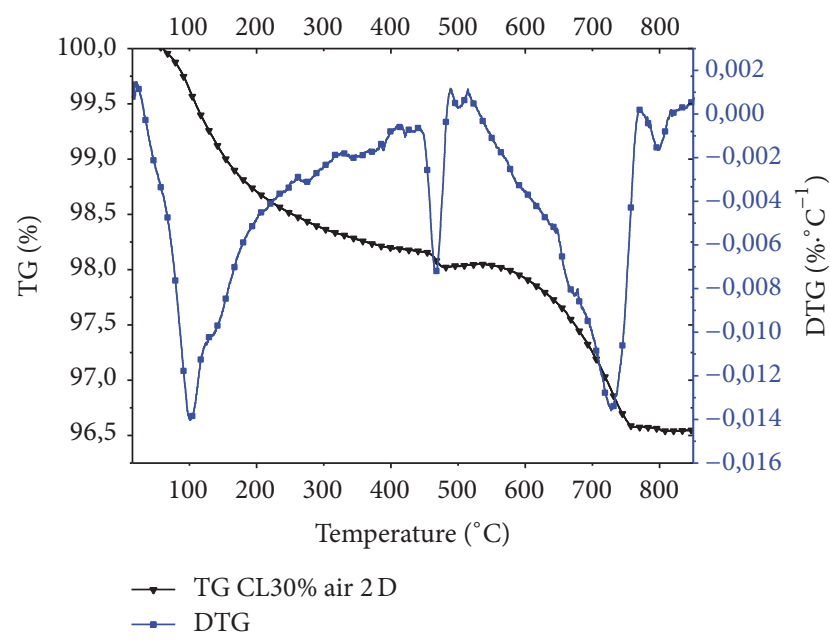

(c)

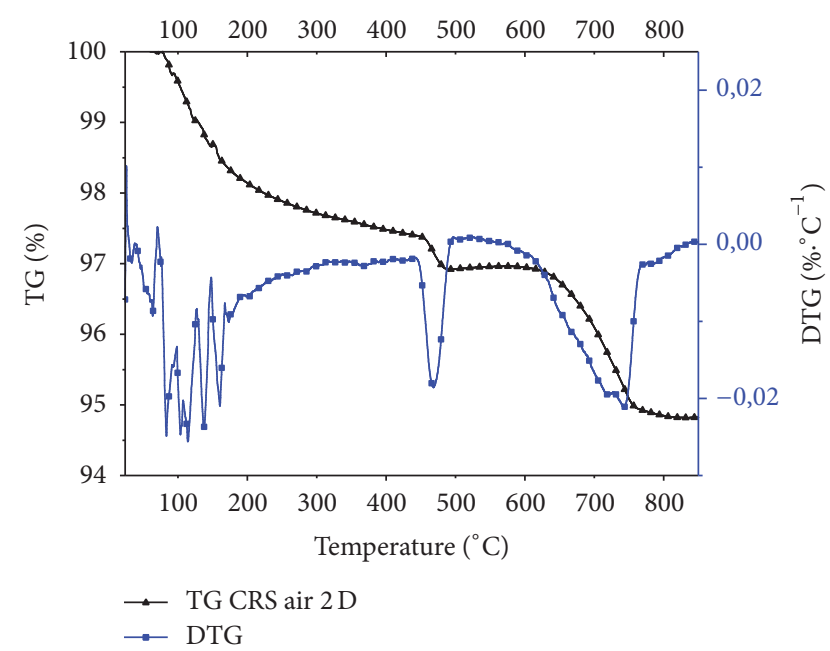

(b)

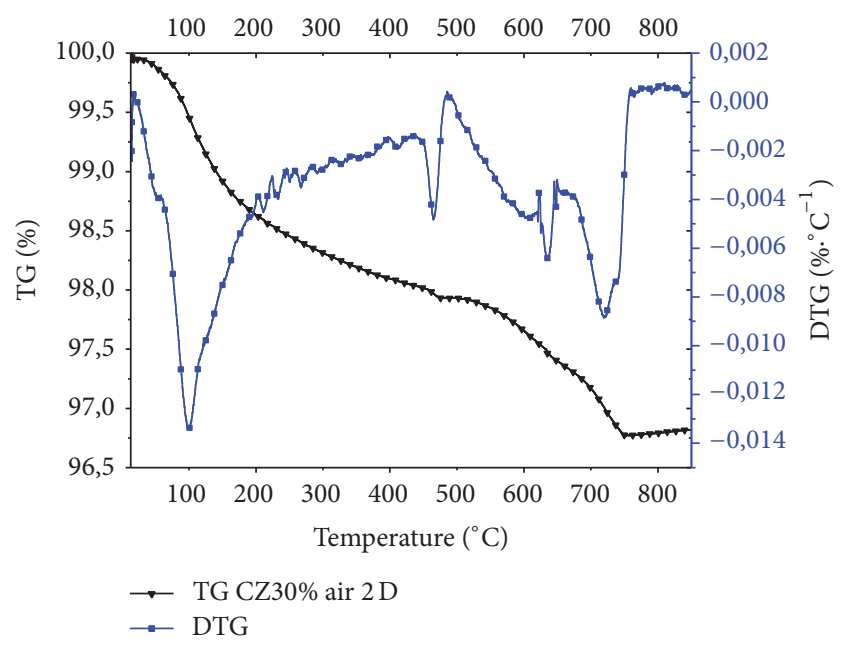

(d)

Figure 4: DTG/TG cement paste preserved on air $\left(\mathrm{RH}=65 \%, \mathrm{~T}=20^{\circ} \mathrm{C}\right)$ for 2 days. (a) CPA/(b) CRS/(c) CL30\% (30\% slag)/(d) CZ3\% (30\% pozzolana).

The formation of calcite during CPA cement carbonation results in the formation of a protective layer on the skin of material which slows down the diffusion of carbon dioxide, so carbonation can be stopped. In the addition-based cement, and in the absence of the quantity of portlandite sufficient to form the protective layer, carbon dioxide diffuses more rapidly [51]. Carbonation in secondary component cement is faster, especially if the mortar has not been kept in moisture environment at the early days [53].

\subsection{Thermogravimetric Analysis}

3.4.1. Thermogravimetric Curves. Figures 4 and 5 show the thermogravimetric curves of the different cement pastes. Three essential endothermic peaks have been observed for all the types:

(1) The peak 50 to $150^{\circ} \mathrm{C}$ : in this section we observe the removal of the adsorbed and free water. We see also the decomposition of CSH part [54].
(2) The peak 105 to $450^{\circ} \mathrm{C}$ : this is the range of decomposition of $\mathrm{CSH}$ and ettringite [54].

(3) The peak 450 to $550^{\circ} \mathrm{C}$ : this is the decomposition of $\mathrm{CH}[54,55]$.

(4) The peak 650 to $750^{\circ} \mathrm{C}$ : this is due to the decarbonation of calcite $\mathrm{CaCO}_{3}[54,56]$, with emissions of $\mathrm{CO}_{2}$ according to the reaction $\mathrm{CaCO}_{3} \rightarrow \mathrm{CaO}+\mathrm{CO}_{2}$.

From Figures 4 and 5, it could be noted that the intensities of peaks on the derivative curves (DTA) decrease with the rise of the percentage of the addition in the composite cement. This indicates that these intensities have a relation with the loss of mass represented by the curves (TG). As it can be seen, the first peak consists of two peaks in the temperature range between $105^{\circ} \mathrm{C}$ and $450^{\circ} \mathrm{C}$, which corresponds to a great loss of mass on the TGA curves. The evaporation of the water molecules resulting from the decomposition of some of the hydrates $(\mathrm{CSH})$ is produced from these two endothermic peaks. The endothermic peak from $105^{\circ} \mathrm{C}$ to $450^{\circ} \mathrm{C}$ becomes 


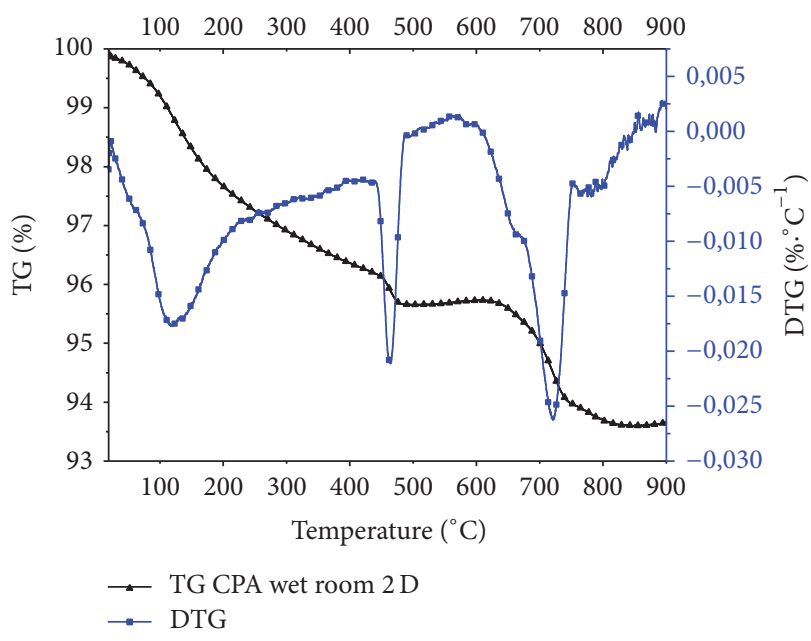

(a)

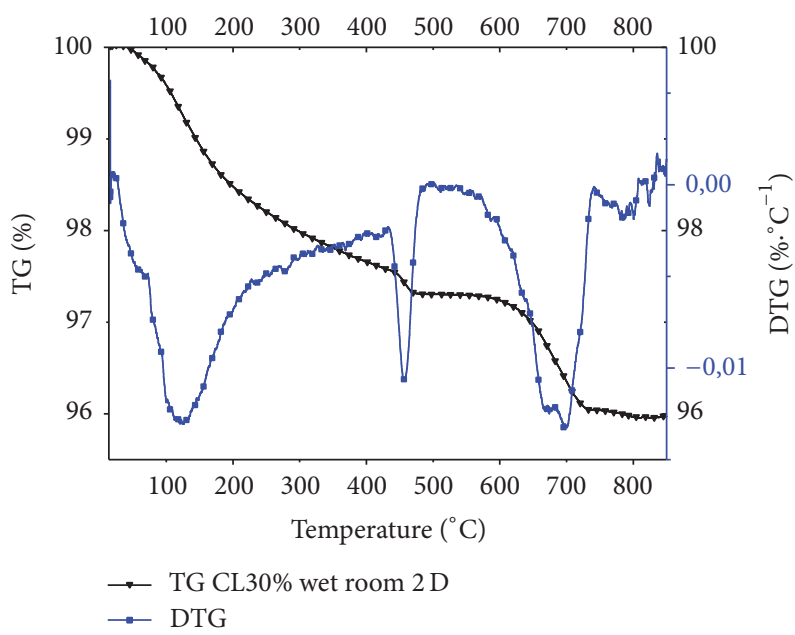

(c)

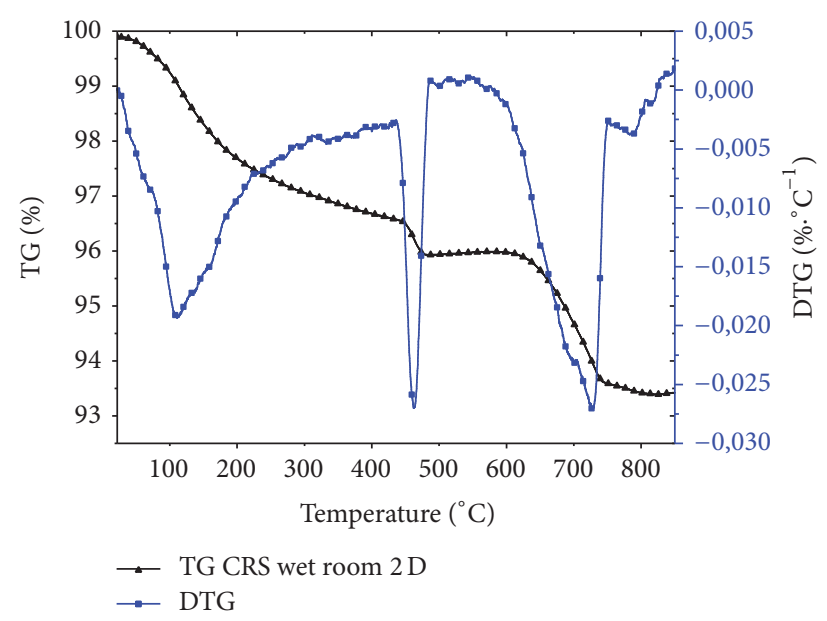

(b)

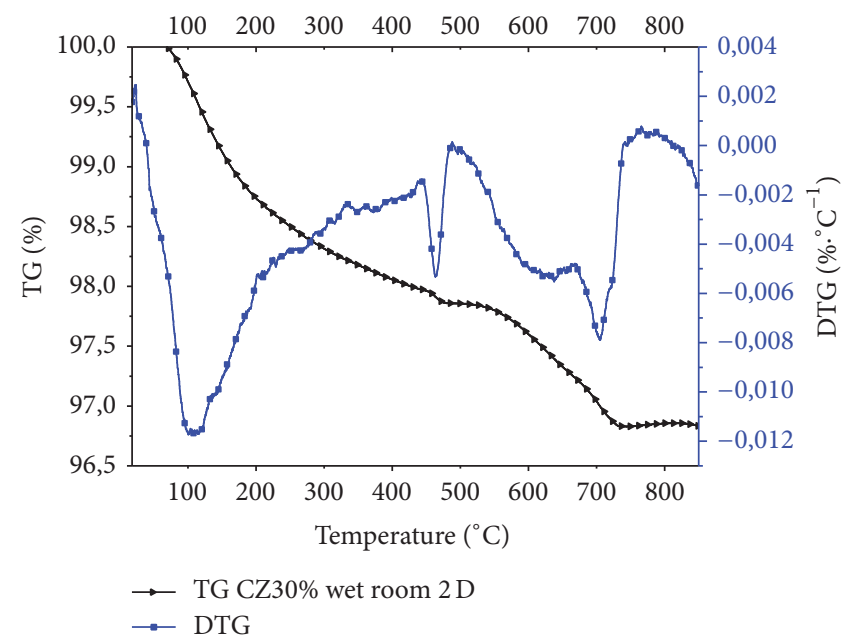

(d)

FIGURE 5: DTG/TG cement paste preserved in wet cure $\left(\mathrm{RH}=95 \%, \mathrm{~T}=20^{\circ} \mathrm{C}\right)$ for 2 days; (a) CPA/(b) CRS/(c) CL30\% (30\% slag)/(d) CZ3\% (30\% pozzolana).

more visible with a high substitution rate; this can be attributed to the contribution of hydration products formation at this age.

The same behavior for Figures 6 and 7 is observed at the 28-day age on the decrease in peak intensity (observed on the DTA curves) with the higher substitution rates of the additions and the conservation medium in the temperature range of $105^{\circ} \mathrm{C}$ to $170^{\circ} \mathrm{C}$ which is probably related to the evaporation of the chemically bound water contained in the other phases of hydration products.

The decomposition of the portlandite at 28 days is found that, in the 2 nd endothermic peak in the DTA curves between $450^{\circ} \mathrm{C}$ and $550^{\circ} \mathrm{C}$, the loss of mass in this range represents the lost water due to the dehydration of $\mathrm{Ca}(\mathrm{OH})_{2}$.

The total $\mathrm{CaCO}_{3}$ content was calculated from the weight loss recorded in the ATG curve between $600^{\circ} \mathrm{C}$ and $800^{\circ} \mathrm{C}$, whose intensity increases with the addition contents as a function of the preservation medium; the loss of weight caused by the $\mathrm{CO}_{2}$ effect is due to the decarbonation of $\mathrm{CaCO}_{3}$.

According to the curves, the calcium hydroxide $\mathrm{Ca}(\mathrm{OH})_{2}$ content of calcium hydroxide for cement stored in the wet conditions is higher than that of air and the $\mathrm{CaCO}_{3}$ content of the cement preserved in the air is more important due to the natural carbonation, highlighting the $65 \%$ drying effect especially on cement with a high additive contents, minus the quantity of portandite produced.

\subsection{Influence of Cement Type and Curing Mode on Weight} Loss. Figures 8(a) and 8(b) show the evolution of the weight loss for the four paste samples containing substitution additions of slag and pozzolana stored for wet and air-cured cement at the age of 2 days.

The weight loss decreases with the substitution rate rising of the addition and under the effect of the curing medium over all the temperature ranges. When the temperature range 


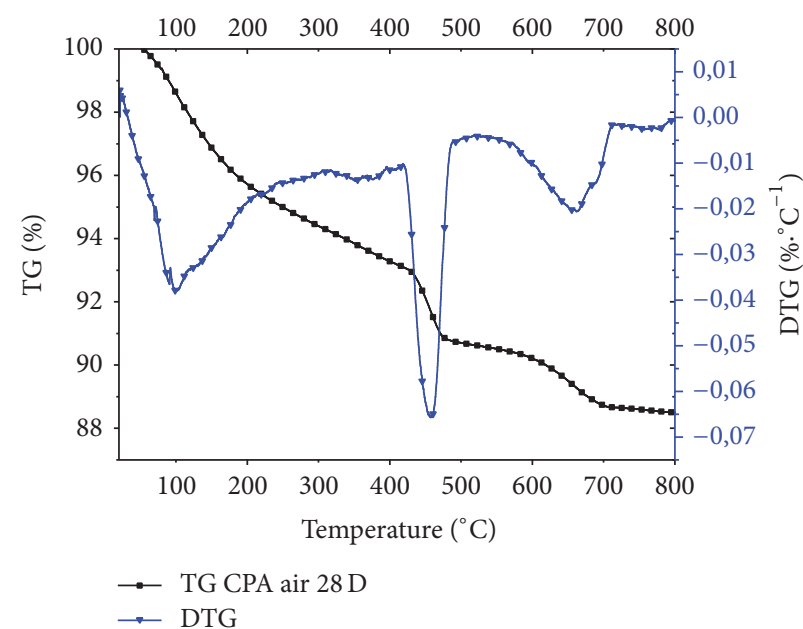

(a)

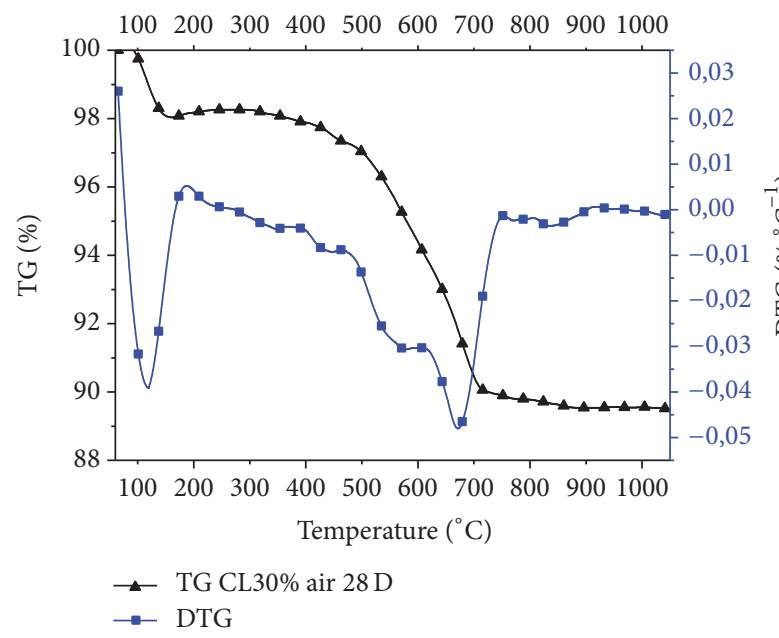

(c)

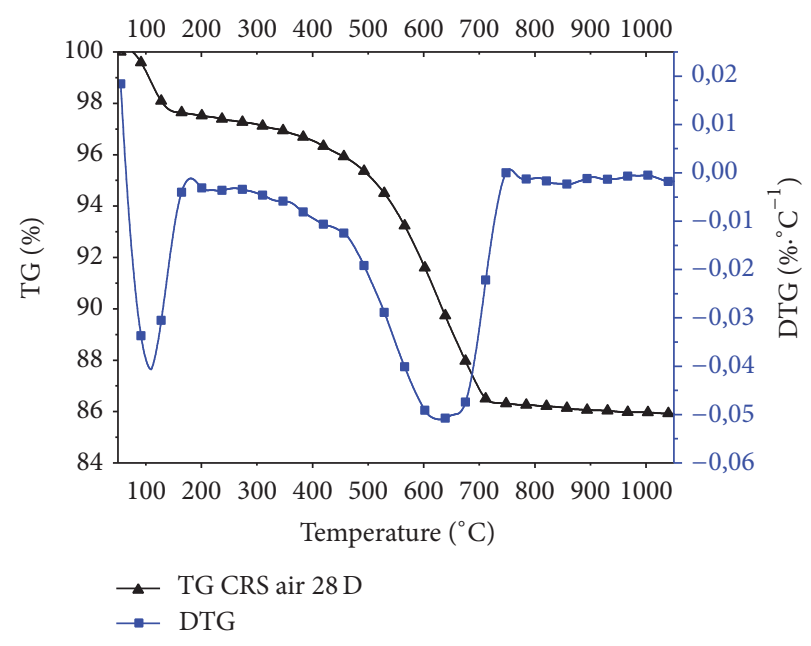

(b)

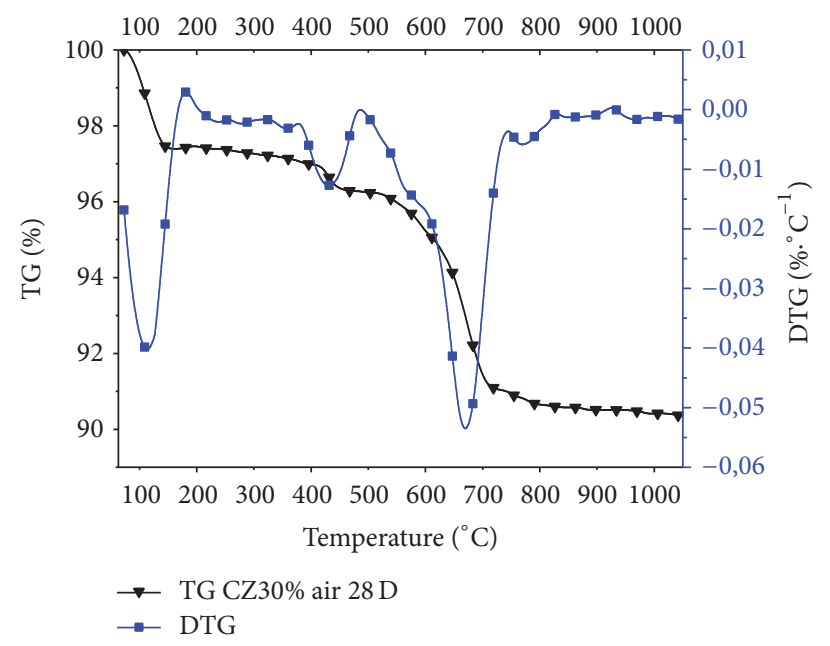

(d)

Figure 6: DTG/TG cement paste preserved on air $\left(\mathrm{RH}=65 \%, \mathrm{~T}=20^{\circ} \mathrm{C}\right)$ for 28 days; (a) CPA, (b) CRS, (c) CL30\% (30\% slag), and (d) CZ3\% (30\% pozzolana).

is between $105^{\circ} \mathrm{C}$ and $450^{\circ} \mathrm{C}$ an important loss of weight is noticed and due to the evaporation of water $\left(\mathrm{H}_{2} \mathrm{O}\right)$ chemically bonded to $\mathrm{CSH}$ hydrates for cement at the age of 2 days in a humid room. They are $3.11 \%, 2.76 \%, 2.08 \%$, and $1.72 \%$ for the samples of artificial Portland cement CPA, CRS, CL30\%, and $\mathrm{CZ} 30 \%$, respectively. For air-cured cement at the age of 2 days they are $2.29 \% 2.13 \%, 1.42 \%$, and $1.4 \%$ for CPA artificial Portland cement, CRS, CL30\%, and CZ30\% samples, respectively.

The weight loss decreases proportionally with the substitution rate of the addition as for the curing medium influence. Replacing a part of cement with mineral additives made the hydration reaction be slower and could result in several effects:

(i) Dilution of the clinker part of the cement with concomitant reduction of the calcium aluminates and silicates content of the cement and consumption of the lime resulting from the hydration of the clinker (the pozzolanic reaction) which occurs at a young age. (ii) Reduction of portlandite content, a compound vulnerable to external attacks [57]. The late reaction of mineral additions is at the origin of this slowing down of hydration; and consequently less weight loss is presented in the amount of evaporated water.

(iii) A reduced amount of hydrated cement consequently decreasing the compressive strength with a greater carbonation depth especially, for cement with a higher addition content preserved in air causing a negative effect on the chemically bound water contained in the CSH hydrates $[4,58]$.

Figures 9(a) and 9(b) show the evolution of the weight loss for the four paste samples containing substitution additions of slag and pozzolana stored for wet and air-cured cement at the age of 28 days.

The results obtained from the loss of weight due to the evaporation of the water chemically bound to the hydrates $\mathrm{CSH}$ for cement preserved in the humid chamber is $7.5 \%$ for 


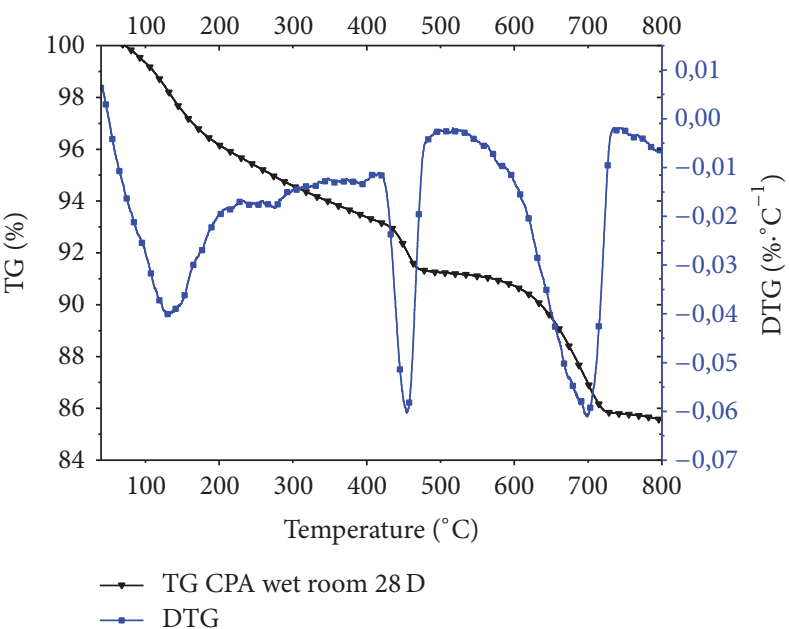

(a)

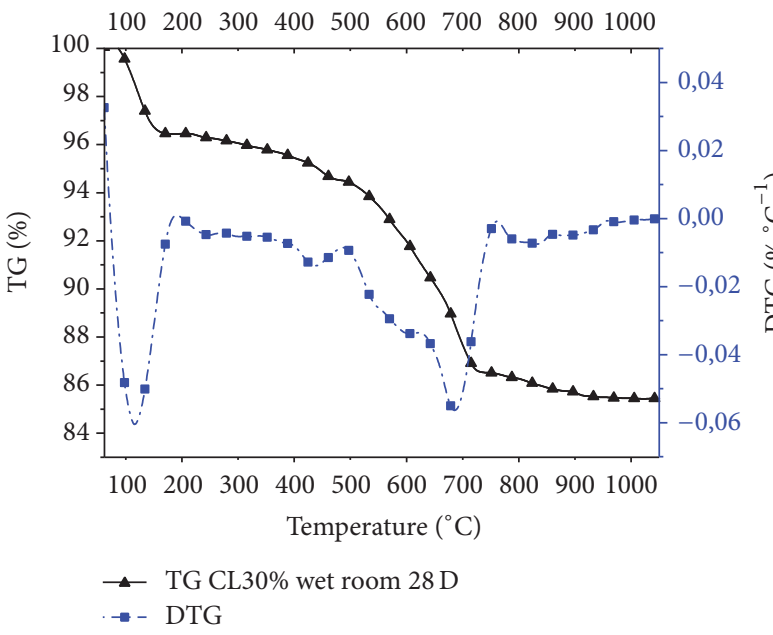

(c)

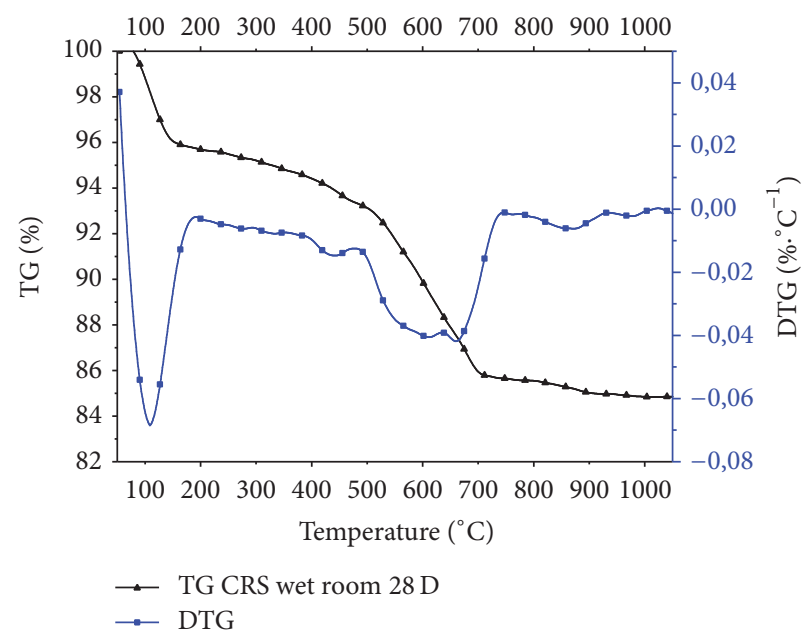

(b)

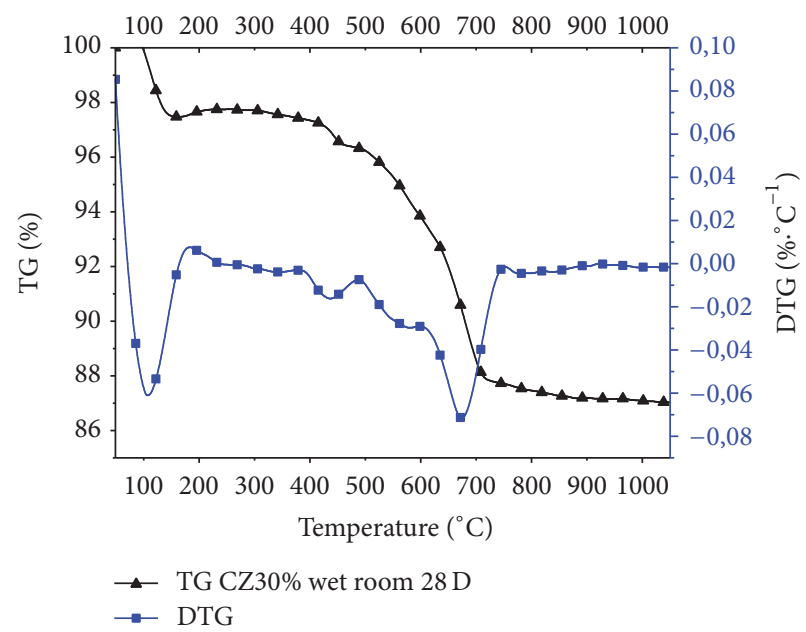

(d)

Figure 7: DTG/TG cement paste preserved in wet cure $\left(\mathrm{RH}=95 \%, T=20^{\circ} \mathrm{C}\right)$ for 28 days: (a) CPA, (b) CRS, (c) CL30\% (30\% slag), and (d) CZ3\% (30\% pozzolana).

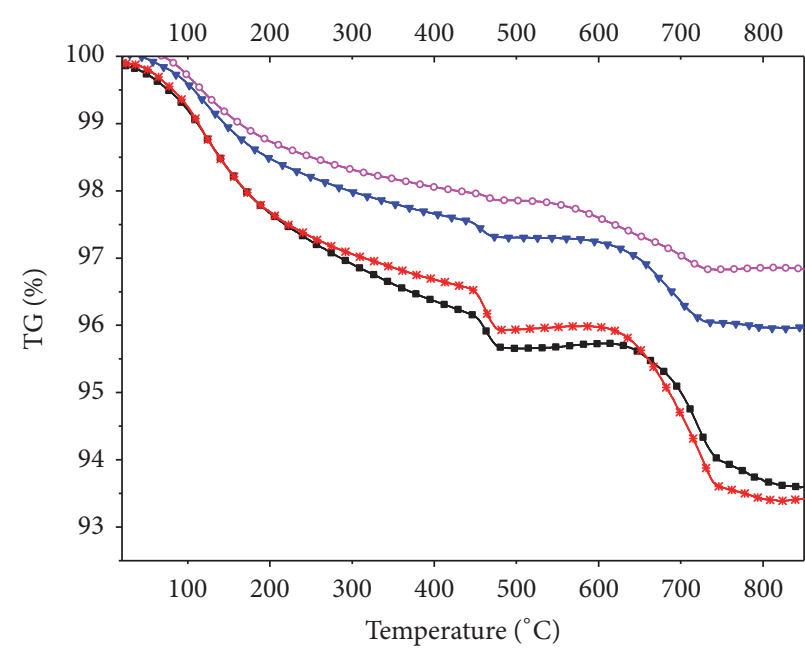

$\begin{array}{ll}\rightarrow \text { CPA wet room 2D } & \rightarrow \text { CL30\% wet room 2D } \\ \rightarrow \text { CRS wet room 2 D } & -\mathrm{CZ30} \% \text { wet room 2 D }\end{array}$

(a) Wet cure

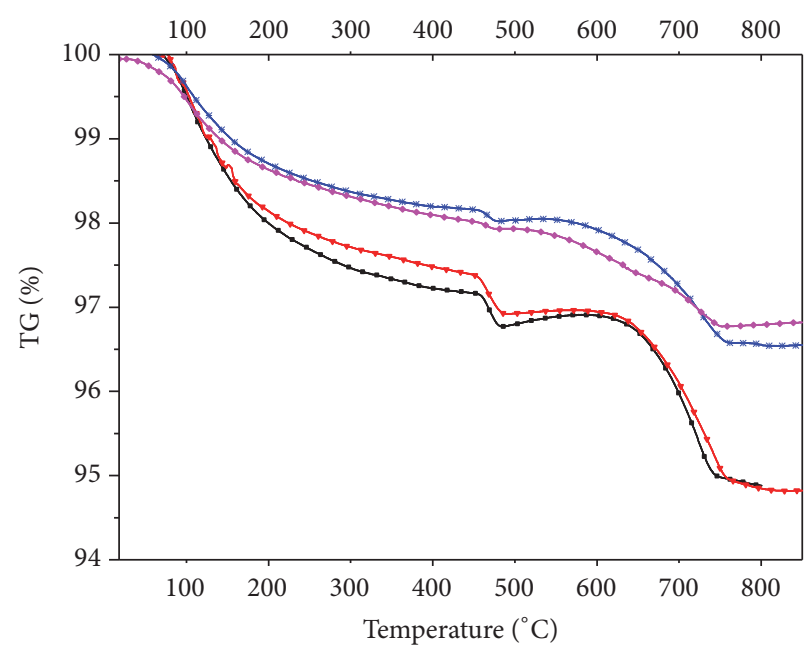

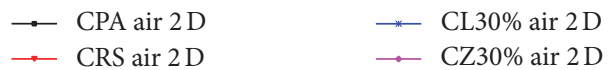

(b) Air

FIGURE 8: (a), (b) Thermogravimetric analysis of cement paste preserved in wet cure and stored in the air for 2 days. 


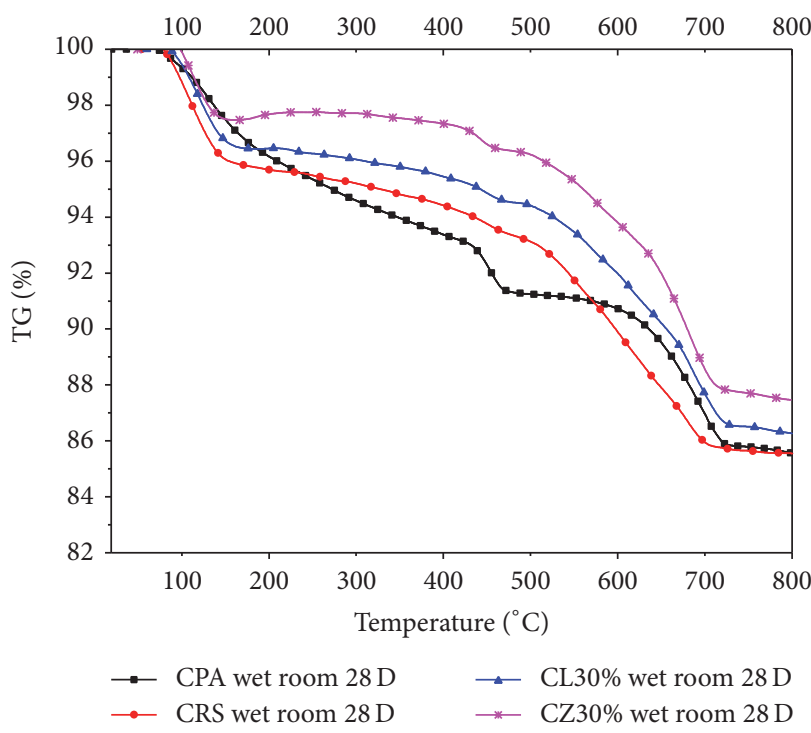

(a) Wet cure

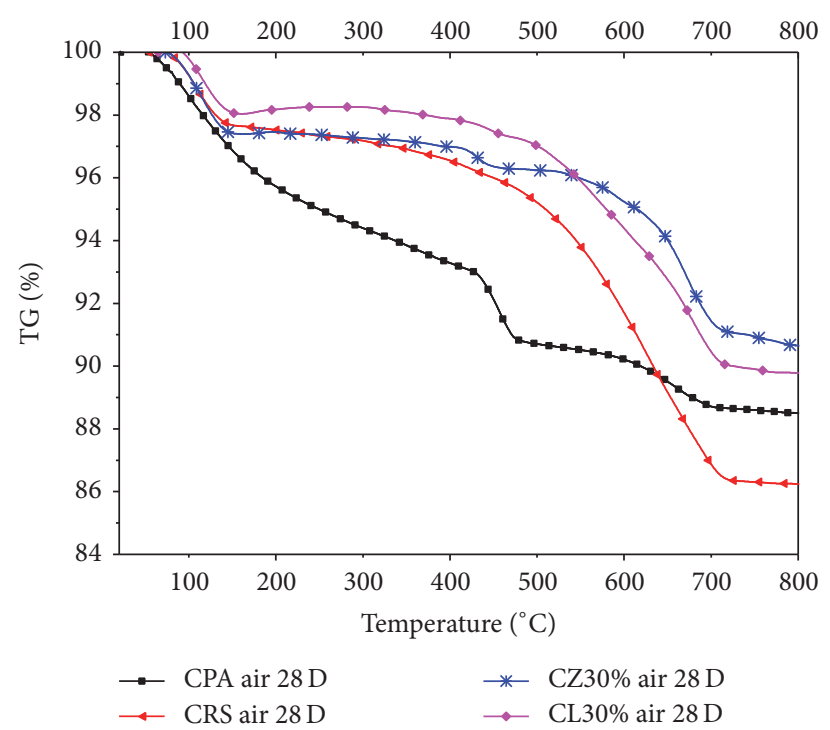

(b) Air

FIgURE 9: (a), (b) Thermogravimetric analysis of cement paste preserved in wet cure and stored in the air for 28 days.

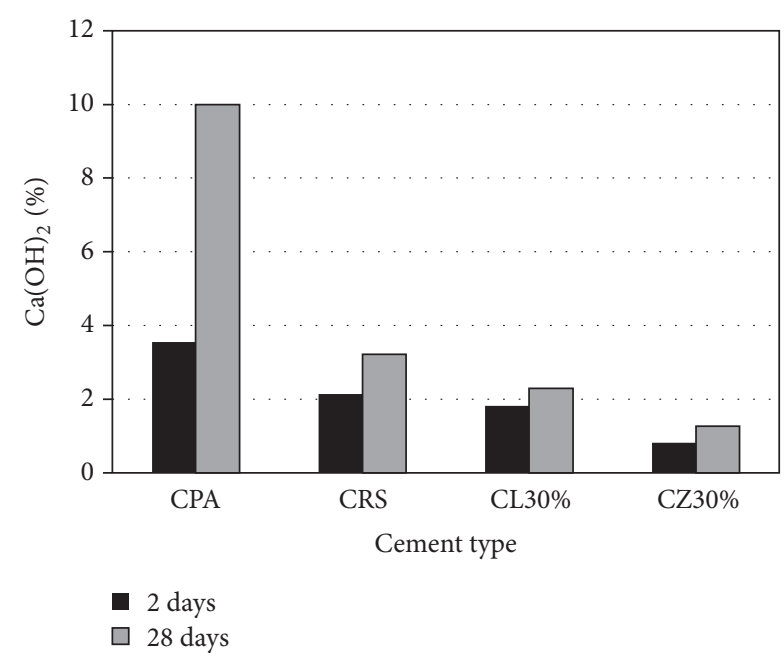

(a) Wet cure

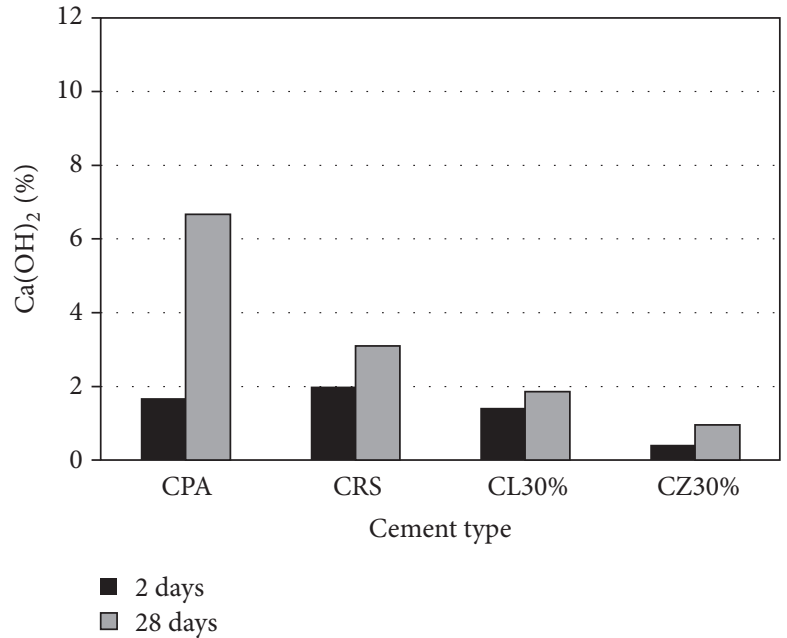

(b) Air

FIgURE 10: (a), (b) The content of retained portlandite in cement paste in wet cure and left in the air for 2 days.

the CPA and 5.04\%, $4.6 \%$, and $3.07 \%$ for the CRS, CL30\%, and CZ30\%, respectively. Thus, for air-cured cement it is about 6.9\% for CPA artificial Portland cement and 3.2\%, 2.2\%, and $2.77 \%$ for samples of CRS, CL30\%, and CZ30\%, respectively.

A clear increase is observed by comparing these values with the results obtained during the cure of 2 days due to the progress of the hydration process.

The evolution of weight loss due to the evaporation of water of the cement preserved in the wet conditions is greater than air, the same observation for portandite content; this is attributed to the hydration reaction process. At $65 \%$ of relative humidity, the portlandite formation is almost stopped for all cement. This can be interpreted by the tendency towards the end of hydration process in this mode of conservation.

\subsection{Evolution of Portlandite Quantity}

3.6.1. The Portlandite Content. Figures 10(a) and 10(b) show the content of portlandite of the cement paste retained in the wet and air-cured at the age of 2 days.

The tests were carried out on cement pastes corresponding to the different compositions. The objective is, on the one hand, the monitoring of the quantity of portlandite and, on the other, the study of the effect of the quantity of portlandite as one of the indicators of durability on the kinetics of natural carbonation.

The method of assaying portlandite and calcium carbonates by TGA is based on the molar masses (atomic); the objective was the control of portlandite quantity and the study 
of its effect as one of durability indicators on the natural carbonation kinetics.

The decomposition of portlandite generally occurs in the temperature range of $450^{\circ} \mathrm{C}$ to $550^{\circ} \mathrm{C}$; its decarbonation takes place in the temperature range of 600 to $800^{\circ} \mathrm{C}$ [59]. The amount of $\mathrm{CH}$ produced which reflects the moisture (pozzolanic or hydraulic) character is estimated by quantifying the loss of mass due to the evaporation of water bound to these hydrates within the temperature range indicated above.

From portlandite's dosage of cement pastes, the profile of the portlandite $\mathrm{Ca}(\mathrm{OH})_{2}$ content of the carbonation mechanism is analyzed.

The portlandite quantity from cement pastes was derived from TGA tests carried out on mass reduced samples shown in Figures 10(a) and 10(b) at 2 and 28 days. The curves show that the quantities of portlandite produced in wet storage medium are higher than those of $65 \%$ relative humidity. Furthermore, we marked the difference between results of conservation methods for all cement.

At 2 days of hydration for a wet cure (cement control) CPA, the portlandite content decreases from $3.55 \%$ to $1.68 \%$ compared to air curing with values from $2.14 \%$ to $2 \%, 1.82 \%$ to $1.42 \%$, and $0.72 \%$ to $0.41 \%$ for the samples of CRS, CL30\%, and CZ30\%, respectively. The same was also observed for 28 days of hydration for a wet cure (cement control) CPA; the content of portlandite decreases from $10 \%$ to $6.57 \%$ compared to air curing from $3.22 \%$ to $3.1 \%, 2.3 \%$ to $1.86 \%$, and $1.27 \%$ to $0.95 \%$ for CRS, CL30\%, and CZ30\% samples, respectively. After 28 days, this can be explained by the decrease in the amount of portlandite as the quantity of portlandite formed is all the more important as the content of mineral additions is lower. This result is in agreement with other research works [60]. It highlights the impact that the initial mineralogical composition has on the behavior of cementitious materials in the face of carbonation as for the portandite content.

As the pozzolanic effect becomes hydrated, the cement releases portlandite ions $\left(\mathrm{Ca}^{++}\right.$and $\left.\mathrm{OH}^{-}\right)$and then, progressively, the pozzolana and/or the slag captures the $\mathrm{Ca}^{++}$ion to form CSH or aluminates. The hydration reaction between Portland cement and a cementitious addition is slower. The slowdown phase has become a dormant phase [61].

Figure 11 shows the content of portlandite as a function of curing medium for all cement types; regarding the curing effect, drying at $65 \%$ relative humidity virtually stopped the formation of portlandite for all cement. This can be interpreted as retarding the hydration process by this mode of preservation [62] which reduces the quantity of capillary water necessary for the continuation of the hydration process.

3.7. Amount of Nonevaporable Water. The dehydration of calcium silicate hydrates (CSH) generally occurs in the temperature range of 105 to $450^{\circ} \mathrm{C}$. The amount of $\mathrm{CSH}$ which reflects the progress of the hydration reaction is estimated by the quantification of the loss of weight due to the evaporation of the water bound to these hydrates; the amount of nonevaporable water was calculated by the following relationship [59]:

$$
\operatorname{NEW}(\%)=\left[\frac{\left(W 105^{\circ}-W 450^{\circ}\right)}{W 450^{\circ}}\right] \times 100
$$

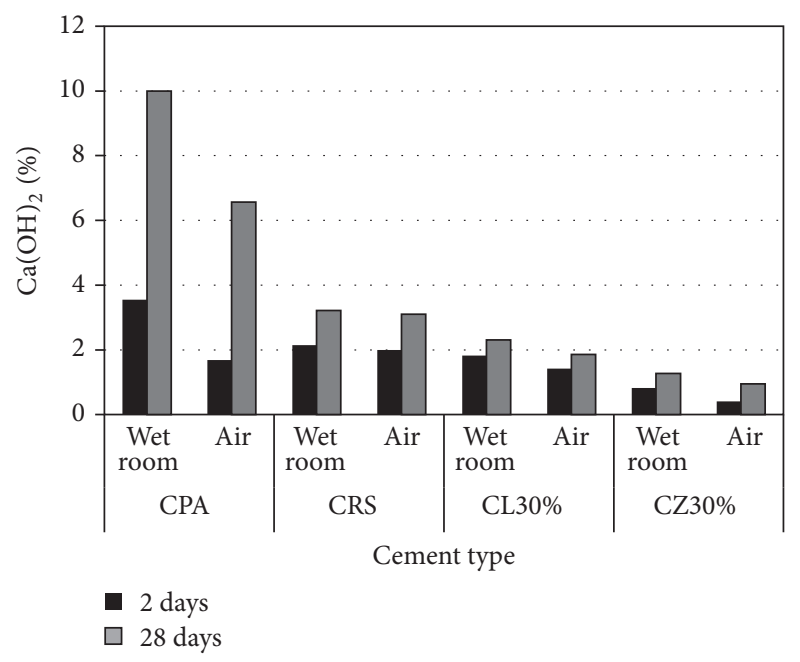

FIGURE 11: The content of portlandite as a function of curing medium for all cement.

where NEW is the amount of nonevaporable water in percentage. $W 105$ is the loss of weight at $105^{\circ} \mathrm{C}$, expressed as a percentage of the mass initial burned. $W 450$ is the loss of weight at $450^{\circ} \mathrm{C}$ expressed as a percentage of the mass initial burned.

The nonevaporable water of the cement as a function of age and the curing medium is represented in Figures 12(a) and $12(\mathrm{~b})$. It is noted that the amount of nonevaporable water is inversely proportional to the increase of the substitution rate of the addition in the cement as a function of age.

Depending on the type of cement, at 2 days of hydration for a wet cure (cement control) CPA, the amount of nonevaporable water (NEW) decreases from $3.11 \%$ to $2.29 \%$ compared to air and $2.76 \%$ to $2.13,2.08 \%$ to $1.42 \%$, and $1.72 \%$ to $1.4 \%$ for the samples of CRS, CL30\%, and CZ30\%, respectively. The same was also observed for 28 days of hydration for a wet cure of CPA (control cement). The amount of nonevaporable water decreases from $7.5 \%$ to $6.9 \%$ when compared to air and $5.04 \%$ to $3.2 \%, 4.6 \%$ to $2.2 \%$, and $3.07 \%$ to $2.77 \%$, respectively, for samples of CRS, CL30\%, and CZ30\%, respectively.

The amount of nonevaporable water (NEW) in the control cement is higher than the compound cement; this is attributed to the degree of polymerization of the $\mathrm{CSH}$ gel and also to the pozzolanic $\mathrm{CH}$-depletion of the composite cement. As the hydration phenomenon is delayed by the presence of secondary additions.

Figure 13 shows the nonevaporable water in relation to the curing medium for all types of cement pastes. The increase of the nonevaporable water is also observed according to the age of 2 days to 28 days. The curves representing the nonevaporable water show a pattern almost similar to those representing the development of the resistances observed for all the cement under the same conditions of hydration. At 2 days, it is observed that the nonevaporable water of the cement increases. These results show that the amount of nonevaporable water is related to the compressive strength, especially at young age ( 2 and 28 days) [59]. This is due to the fact that the incorporation of the secondary additions into the cement 


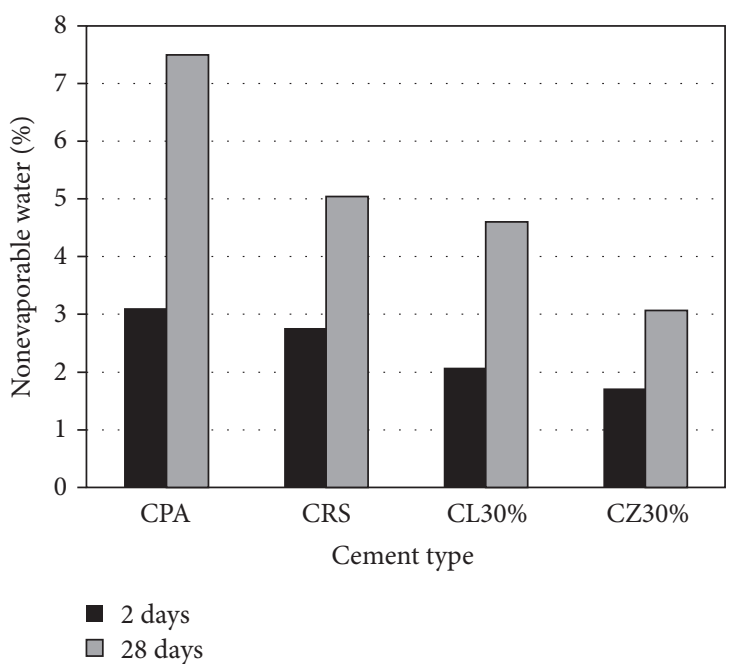

(a) Wet cure

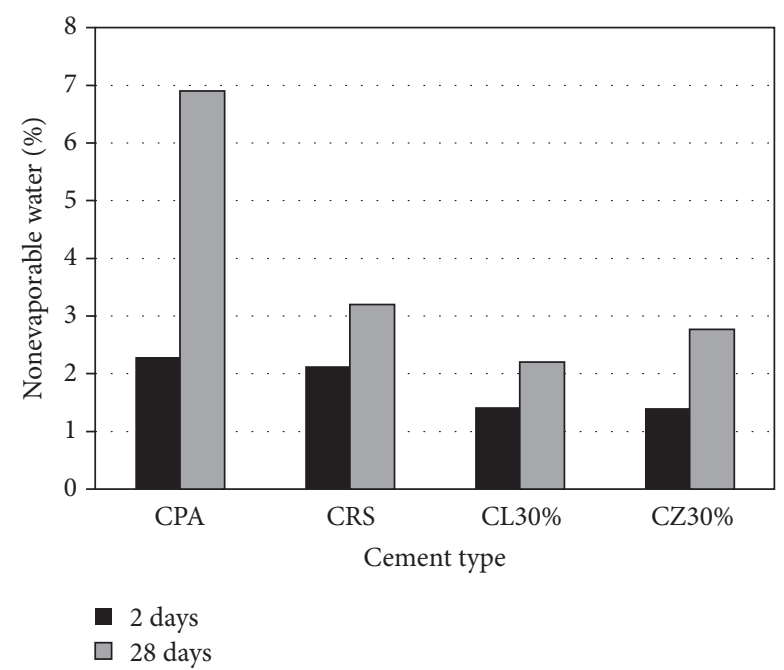

(b) Air

Figure 12: (a), (b) Nonevaporable water of cement pastes retained in the wet cure and air at 2 days.

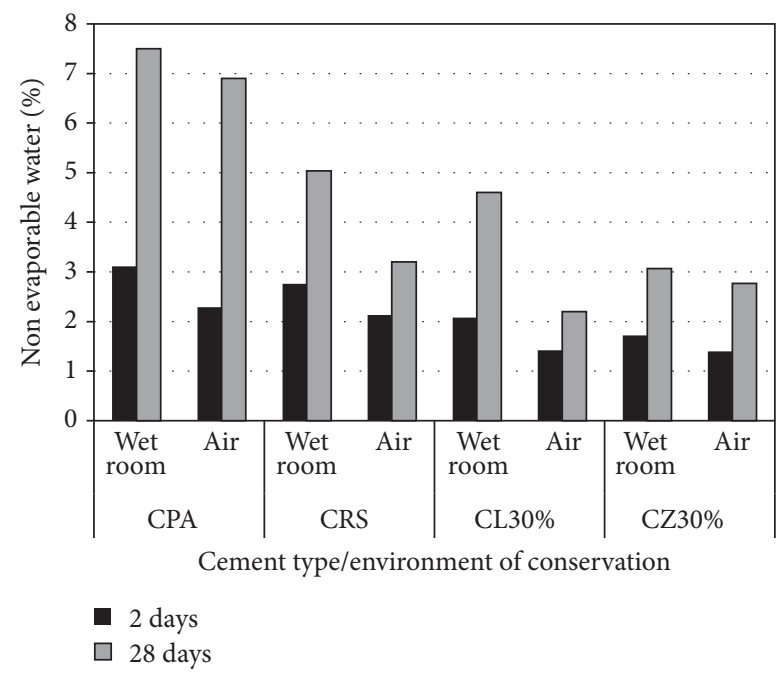

FIGURE 13: Nonevaporable water in relation to curing medium for types of cement.

systematically leads to a reduction of the inorganic compounds $\mathrm{C}_{2} \mathrm{~S}$ and $\mathrm{C}_{3} \mathrm{~S}$. The latter are the main minerals which ensure the development of resistances in the short and medium term.

\subsection{The Correlations}

3.8.1. Correlation between Portlandite and Carbonation. As can be seen from Figure 14, for the two curing media, the correlation is acceptable for that in air $\left(R^{2}=0.7343\right)$, and it is not too strong for that preserved in water $\left(R^{2}=0.3512\right)$, although this tendency is coherent. Carbonation kinetics are influenced by the quantity of carbonation parts including portlandite [17]. The depth of carbonation decreases as the quantities of portlandite measured rise. For the case of water curing, the quantities of portlandite are larger than that preserved in the air.

3.8.2. Correlation between Portlandite and Compressive Strength. The trend curves in the Figure 15 show an acceptable correlation for both cure types $\left(R^{2}=0.8192, R^{2}=0.5488\right)$. The quantities of portlandite produced in the case of wet conservation are higher than those stored at $65 \%$ relative humidity. Secondly, the difference between the results of the two conservation methods is marked for all the cement. These results show the content of portlandite was related to compressive strength [59]. This is due to the fact of introducing the secondary additions, which leads to a reduction of $\mathrm{C}_{3} \mathrm{~S}$ and $\mathrm{C}_{2} \mathrm{~S}$ compounds.

\subsubsection{Correlation between Natural Carbonation and Com-} pressive Strength. As a function of the general tendency for the two curing media, Figure 16 shows a good correlation; the reduction of the carbonation depths of the mortars studied with the increase of their compressive strengths is in agreement with the literature.

For the mechanical strength as a function of carbonation, the proposed correlation coefficients give a good correlation for the two media $\left(R^{2}=0.9274, R^{2}=0.9889\right)$ with the experimental values; this correlation measurement of the resistance makes it possible to estimate the durability regarding the carbonation.

3.8.4. Correlation between Portlandite and Nonevaporable Water. A good correlation exists between the two quantities (Figure 17), for the two types of treatment $\left(R^{2}=0.9198, R^{2}=\right.$ 0.9083 ). The decrease of the nonevaporable water of the pure pastes studied also leads to the decrease in the content of portlandite revealing a good agreement. 


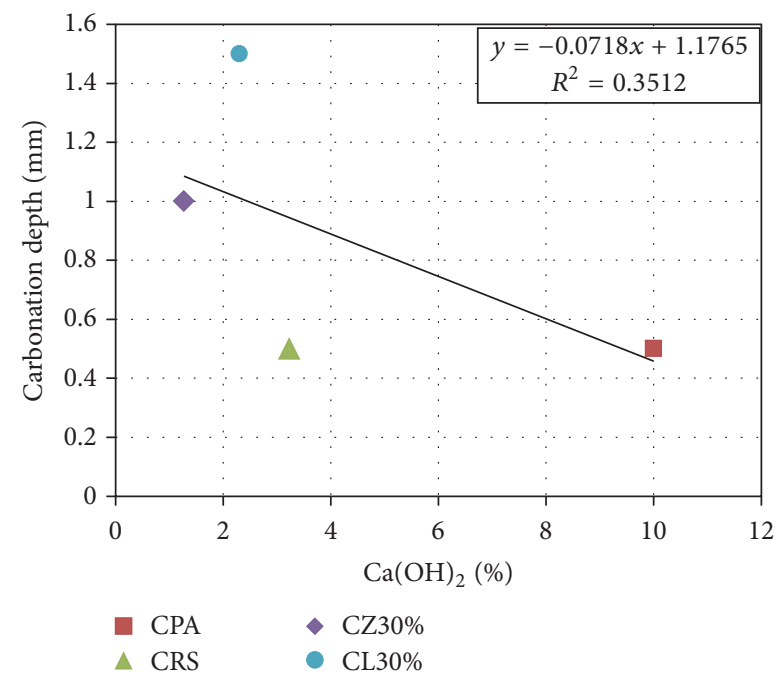

(a) Wet cure

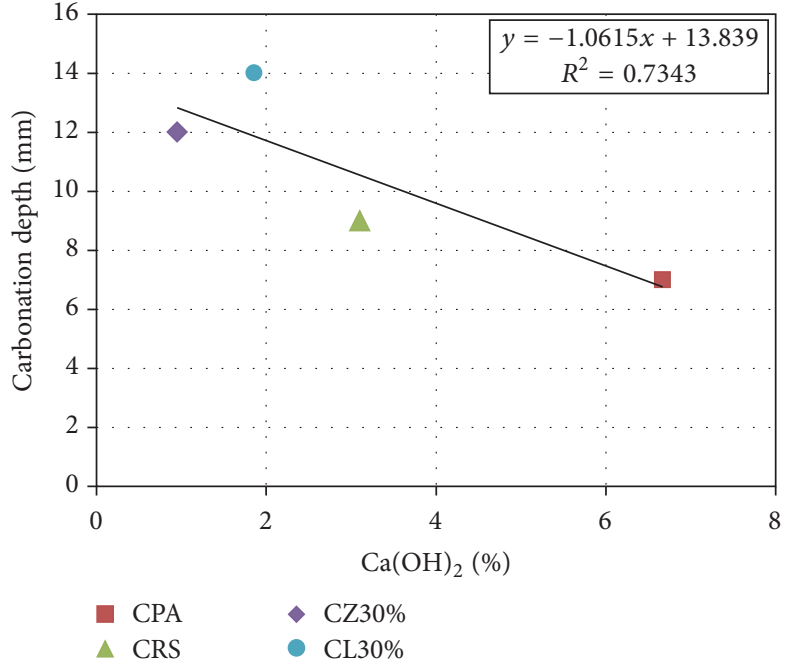

(b) Air

FIgURE 14: Portlandite content as a function of carbonation depth.

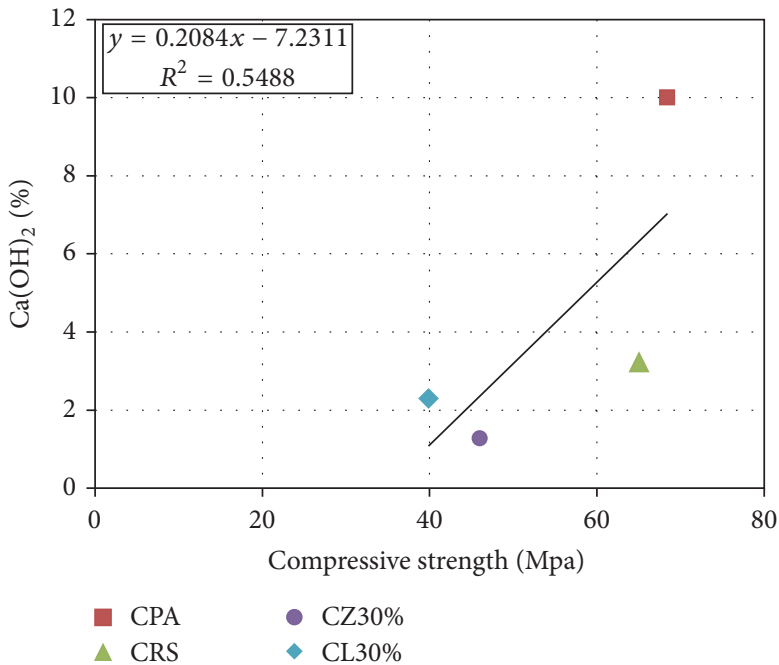

(a) Wet cure

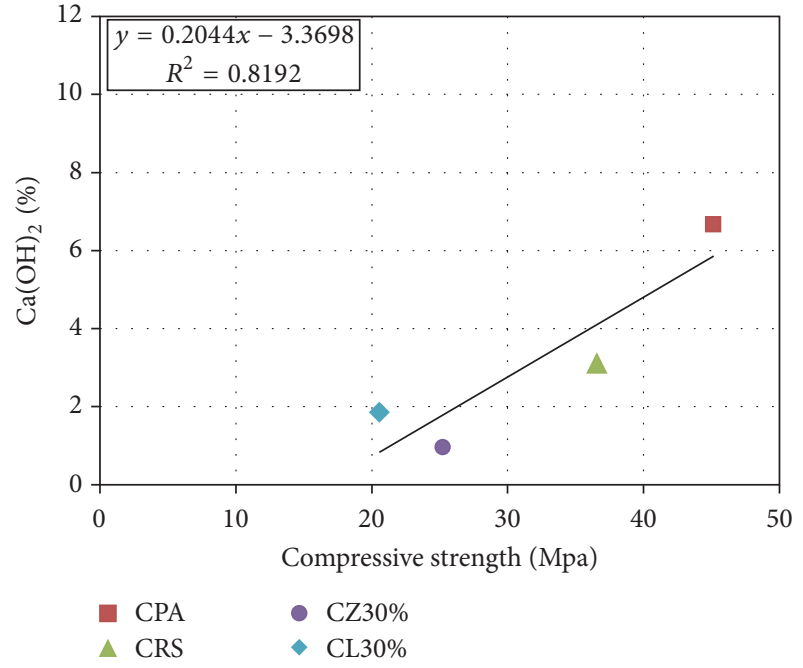

(b) Air

FIGURE 15: Portlandite content as a function of compressive strength.

Nonevaporable water is estimated by quantifying the loss of weight due to the evaporation of chemically bound water in the range of $150-450^{\circ} \mathrm{C}$ due to the decalcification of portlandite. This content for the samples conserved in the humid room is greater than that for air conservation, which reflects the amount of $\mathrm{CSH}$ due to the progress of the hydration reaction, the same findings for the content of the portandite; this is attributed to the progress of the hydration reaction. On the other, hand drying at $65 \%$ relative humidity almost stopped the formation of portlandite for all the compositions studied.

The amount of nonevaporable water (NEW) in the control cement is higher than the compound cement; this is attributed to the degree of polymerization of the CSH gel and also to the pozzolanic $\mathrm{CH}$-depletion of the composite cement. Thus, the hydration phenomenon is delayed by the presence of secondary additions.
3.8.5. Correlation between Compressive Strength and Nonevaporable Water. The curves represented in Figure 18 show the nonevaporable water with an almost similar appearance to those representing the development of the resistances observed for all the cement under the same hydration conditions $\left(R^{2}=0.5513, R^{2}=0.7962\right)$. Evaporation of the cement increases with the decrease in the substitution of the addition. These results show that the amount of nonevaporable water is related to the compressive strength.

\section{Conclusion}

This work aims to quantify the effects of wet cure duration on the different chemical and mechanical properties of oneyear-old mortars and cement pastes mainly and the durability regarding natural carbonation and compressive strength as 


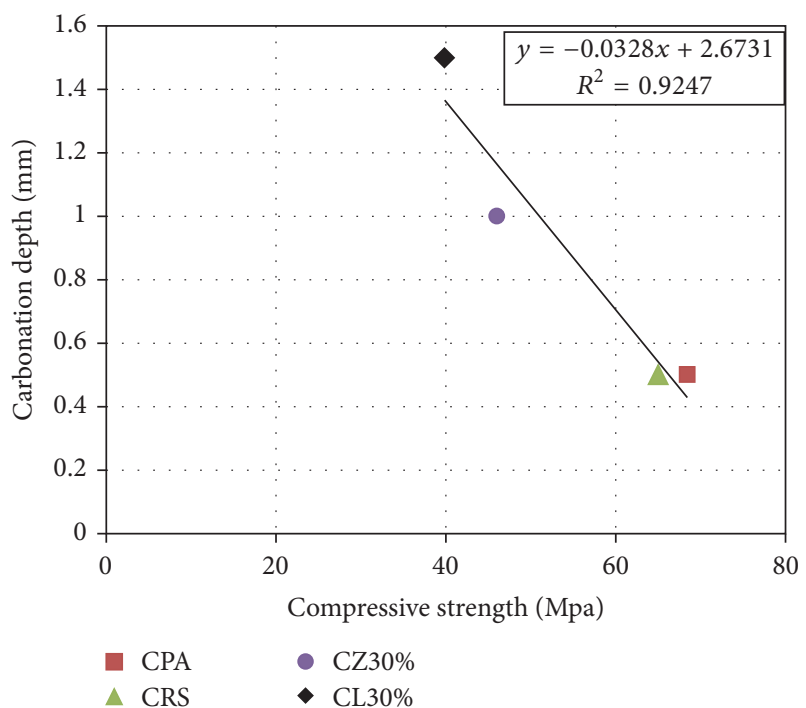

(a) Wet cure

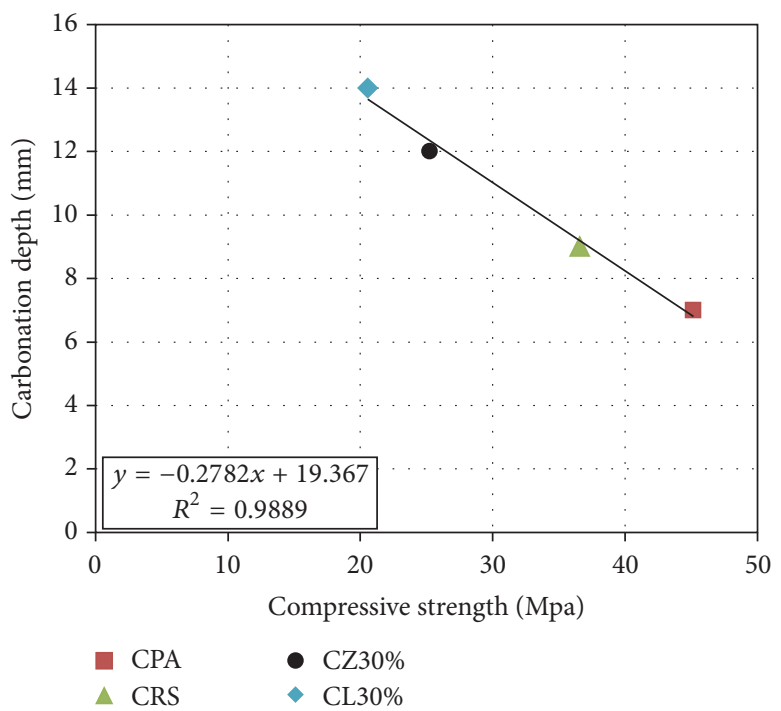

(b) Air

FIGURE 16: Carbonation depth as a function of compressive strength.

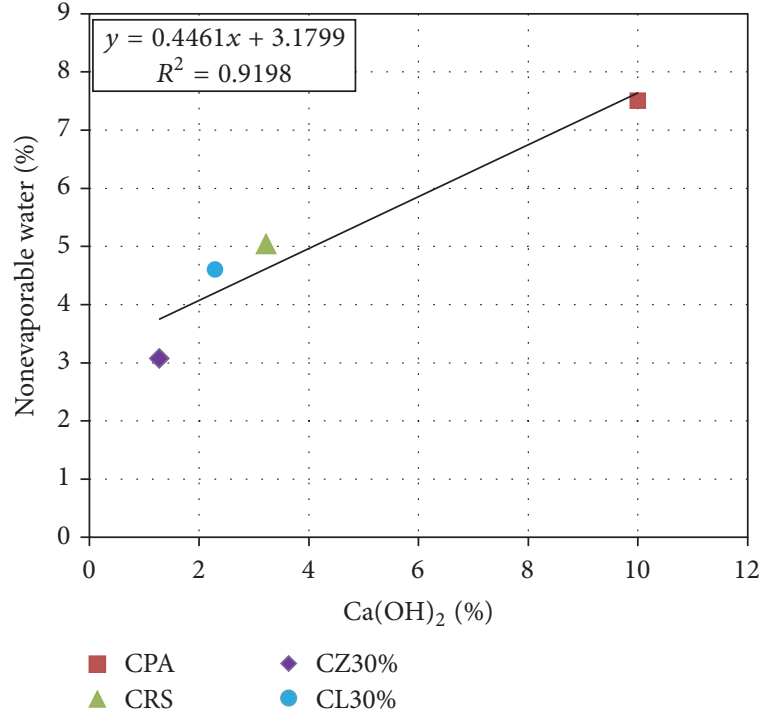

(a) Wet cure

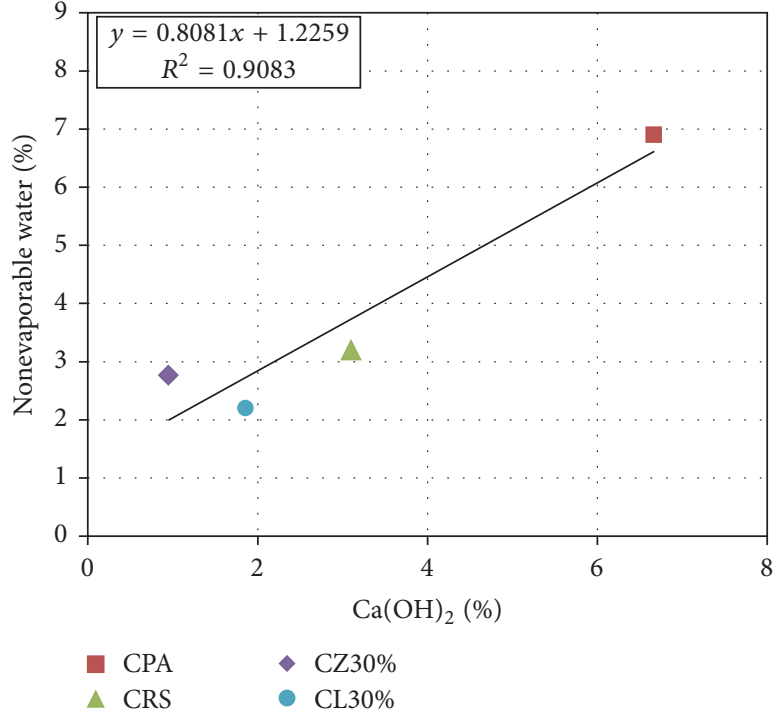

(b) Air

FIGURE 17: Portlandite content as a function of nonevaporable water.

studied characteristics. The investigation by thermogravimetric analysis on the cement paste allowed us to build a more clear idea at the level of the microstructure and to highlight the good correlation between the parameters seen by this analysis and the properties of mortars studied. The characteristics studied are strongly related to the wet curing regime and the influence of cement type. The results obtained from this research allow us to draw the following conclusions:

(i) The curing regime period and clinker have a significant effect and improvement of mortars properties. It has been noticed that the extension of the curing regime has a marked effect on the compressive strength.

(ii) The influence of cement type is more significant for mortars with low addition dosages; the compressive strength of CEMII/BS and CEMII/BP cement is much lower than those of CEMI52.5 and CEMII42.5; this was explained by the slowing down of hydration because of the low clinker content.

(iii) The carbonation depth is greater for the CEMII/BS and CEMII/BP test specimens compared to CEMI52.5 and CEMII42.5; this effect is in part attributed to 


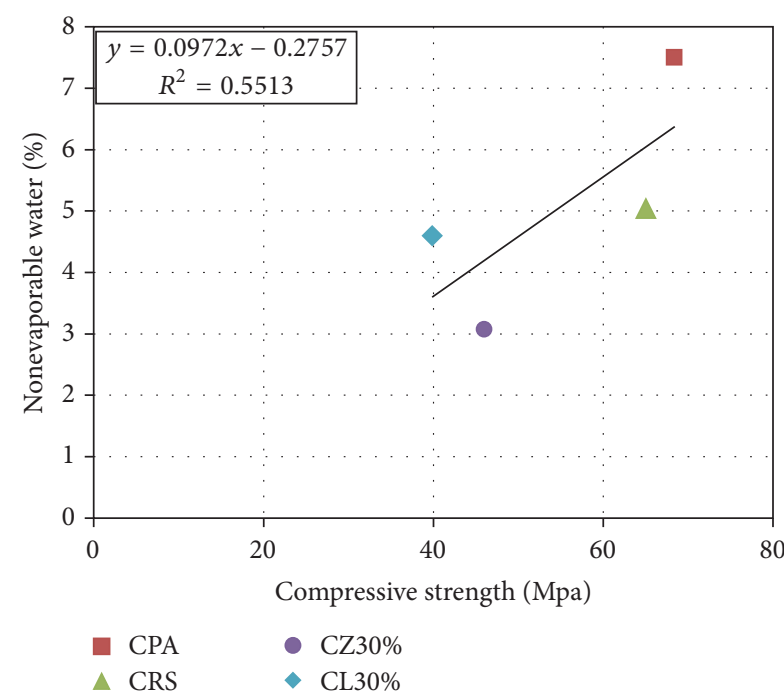

(a) Wet cure

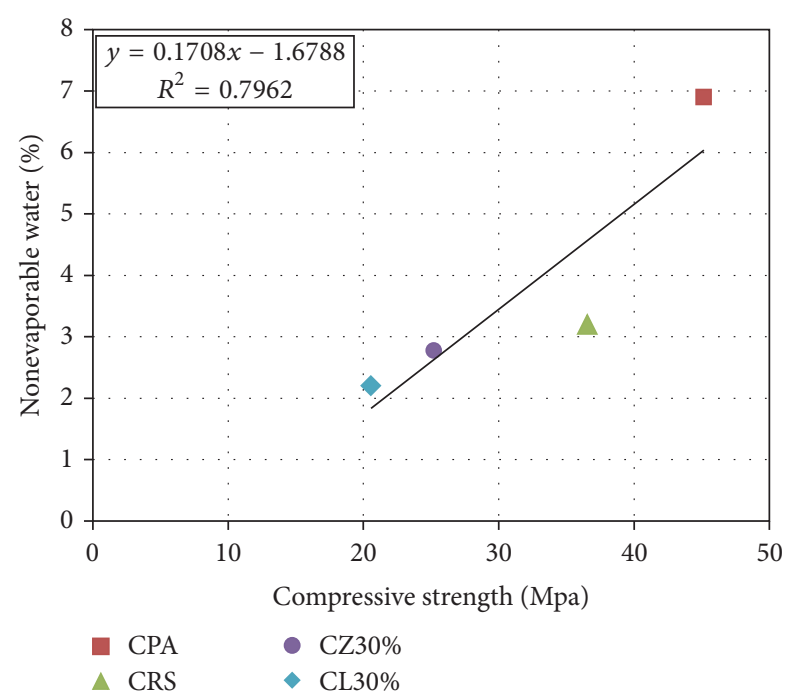

(b) Air

FIGURE 18: Nonevaporable water as a function of compressive strength.

the low clinker content and therefore the content of portlandite $\mathrm{Ca}(\mathrm{OH})_{2}$ and the pozzolanic activity.

(iv) The thermogravimetric analysis (TGA) is the most optimized method for investigating natural carbonation in mortars and cement pastes.

(v) The analysis by DTA/TG shows the influence of the type of cement on the loss of weight and the content of portlandite.

(vi) The quantity of portlandite is inversely proportional to the increase in the substitution rate of the addition for all ages.

(vii) The cement hydration is delayed by the pozzolanic activity of the addition, which is explained by the greater carbonation depth and a lower portlandite content.

(viii) A good correlation exists between compressive strength and natural carbonation. An almost linear relationship has been observed between different mortars and resistance increases when carbonation decreases.

(ix) Portlandite content is increasing as a function of the compressive strength and the inversely is decreasing in regard to the natural carbonation.

(x) The nonevaporable water contained in the hydrates which reflects the rate of advance of the hydration is used to determine the degree of hydration of the blended cement.

(xi) The quantity of nonevaporable water is inversely proportional to the increase in the substitution rate of the addition for all ages.

(xii) The correlation between portlandite content, compressive strength, and natural carbonation was satisfactorily performed; the portlandite content seemed to be an important parameter in the prediction of the resistance of mortars and their durability.

\section{Conflicts of Interest}

The corresponding author Miss Saida Boualleg declares that there are no conflicts of interest for the author and coauthors regarding the present submitted article.

\section{References}

[1] J. I. Escalante-García and J. H. Sharp, "Effect of temperature on the hydration of the main clinker phases in portland cements: part II, blended cements," Cement and Concrete Research, vol. 28, no. 9, pp. 1259-1274, 1998.

[2] L. N. Plummer and E. Busenberg, "The solubilities of calcite, aragonite and vaterite in $\mathrm{CO}_{2}-\mathrm{H}_{2} \mathrm{O}$ solutions between 0 and $90 \circ \mathrm{C}$, and an evaluation of the aqueous model for the system $\mathrm{CaCO}_{3}-\mathrm{CO}_{2}-\mathrm{H}_{2} \mathrm{O}$," Geochimica et Cosmochimica Acta, vol. 46, no. 6, pp. 1011-1040, 1982.

[3] G. W. Groves, D. I. Rodway, and I. G. Richardson, "The carbonation of hardened cement pastes," Advances in Cement Research, vol. 3, no. 11, pp. 117-125, 1990.

[4] J. I. Escalante-Garcia, "Nonevaporable water from neat OPC and replacement materials in composite cements hydrated at different temperatures," Cement and Concrete Research, vol. 33, no. 11, pp. 1883-1888, 2003.

[5] E. Vejmelková, M. Keppert, P. Rovnaníková, Z. Keršner, and R. Černý, "Properties of lime composites containing a new type of pozzolana for the improvement of strength and durability," Composites Part B: Engineering, vol. 43, no. 8, pp. 3534-3540, 2012.

[6] E. Özbay, O. Karahan, M. Lachemi, K. M. A. Hossain, and C. D. Atis, "Dual effectiveness of freezing-thawing and sulfate attack on high-volume slag-incorporated ECC," Composites Part B: Engineering, vol. 45, no. 1, pp. 1384-1390, 2013. 
[7] N. Rafaï, H. Hornain, G. Villain, V. B. Bouny, G. Platret, and T. Chaussadent, "Comparison and validity of methods for measuring the carbonation," French Journal of Civil Engineering, vol. 6, no. 2, pp. 251-274, 2002.

[8] V. G. Papadakis, C. G. Vayenas, and M. N. Fardis, "Physical and chemical characteristics affecting the durability of concrete," ACI Materials Journal, vol. 88, no. 2, pp. 186-196, 1991.

[9] R. Miragliotta, Modeling physicochemical process of carbonation prefabricated concrete consideration of wall effects [Ph.D. thesis], University of Rochelle, La Rochelle, France, 2000.

[10] R. S. Mikhail, S. A. Abo-El-Enein, and N. A. Gabr, "Hardened slag-cement pastes of various porosities I. Compressive strength, degree of hydration and total porosity," Journal of Applied Chemistry and Biotechnology, vol. 24, no. 12, pp. 735743, 1974.

[11] S. A. Abo-El-Enein, M. Daimon, S. Ohsawa, and R. Kondo, "Hydration of low porosity slag-lime pastes," Cement and Concrete Research, vol. 4, no. 2, pp. 299-312, 1974.

[12] Q. Yu, K. Sawayama, S. Sugita, M. Shoya, and Y. Isojima, "Reaction between rice husk ash and $\mathrm{Ca}(\mathrm{OH})_{2}$ solution and the nature of its product," Cement and Concrete Research, vol. 29, no. 1, pp. 37-43, 1999.

[13] M. A. Chikouche, E. Ghorbel, and M. Bibi, "The possibility of using dredging sludge in manufacturing cements: optimization of heat treatment cycle and ratio replacement," Construction and Building Materials, vol. 106, pp. 330-341, 2016.

[14] M. Frías and J. Cabrera, "Influence of MK on the reaction kinetics in MK/lime and MK-blended cement systems at 20॰C," Cement and Concrete Research, vol. 31, no. 4, pp. 519-527, 2001.

[15] C. Shi and R. L. Day, "Pozzolanic reaction in the presence of chemical activators. Part I. Reaction kinetics," Cement and Concrete Research, vol. 30, no. 1, pp. 51-58, 2000.

[16] B. Baroguel, "Concrete design for a lifetime of data control works with regard to the durability and corrosion of alkaline frameworks state of the art and guidance for the implementation of a performential approach based on of French indicator of sustainability," Association Civil Engineering, June 2004.

[17] V. G. Papadakis, "Effect of supplementary cementing materials on concrete resistance against carbonation and chloride ingress," Cement and Concrete Research, vol. 30, no. 2, pp. 291299, 2000.

[18] B. Jaques and J. P. Ollivier, The Data Bases Concrete for Their Formulation, Technical Industry Association Hydraulic Binders, Press the National School of Bridges and Shod, Eyrolles, 1996.

[19] M. Thiery, P. Dangla, G. Villain et al., A Hydration Model for Calculating the Content of Cementitious Materials Porltandite as Now of Models of Carbonations, Central Laboratory of Ponts et Chausses, Paris, France, 2004.

[20] Ö. Çakir and F. Aköz, "Effect of curing conditions on the mortars with and without GGBFS," Construction and Building Materials, vol. 22, no. 3, pp. 308-314, 2008.

[21] A. M. Neville, Properties of Concrete, Longman Scientific and Technical, 3rd edition, 1992.

[22] C. Vernet, Chemical Stability of Hydrates-Defense Mechanism of Concrete against Chemical Attacks, The Durability of Concrete, Presses of l'ENPC, 1992.

[23] J. P. Balayssac, Ch. H. Détriché, and J. Grandet, "Effects of curing upon carbonation of concrete," Construction and Building Materials, vol. 9, no. 2, pp. 91-95, 1995.

[24] ACI Committee 308, "Guide to curing concrete," Journal Proceeding ACI, vol. 9, no. 2, pp. 233-242, 1971.
[25] ACI Committee 308, Recommended Practice for Curing Concrete $M C P$, American Construction Institute, ACI Committee, Farmington Hills, Mich, USA, 1998.

[26] F. Sajedi and H. A. Razak, "Effects of curing regimes and cement fineness on the compressive strength of ordinary Portland cement mortars," Construction and Building Materials, vol. 25, no. 4, pp. 2036-2045, 2011.

[27] A. E. Abalaka and O. G. Okoli, "Effects of limited initial curing durations on mechanical properties of concrete," Journal Civil Engineering Construction Technology, vol. 4, no. 3, pp. 104-109, 2013.

[28] P.-C. Aitcin, B. Miao, W. D. Cook, and D. Mitchell, "Effects of size and curing on cylinder compressive strength of normal and high-strength concrete," ACI Materials Journal, vol. 91, no. 4, pp. 349-354, 1994.

[29] N. Shafiq and J. G. Cabrera, "Effects of initial curing condition on the fluid transport properties in OPC and fly ash blended cement concrete," Cement and Concrete Composites, vol. 26, no. 4, pp. 381-387, 2004.

[30] G. De Schutter and K. Audenaert, "Evaluation of water absorption of concrete as a measure for resistance against carbonation and chloride migration," Materials and Structures, vol. 37, no. 273, pp. 591-596, 2004.

[31] J. P. Balayssac, C. H. Détriché, and N. Diafat, "Effect of wet curing duration upon cover concrete characteristics," Materials and Structures, vol. 31, no. 209, pp. 325-328, 1996.

[32] H. Binici, O. Aksogan, I. H. Cagatay, M. Tokyay, and E. Emsen, "The effect of particle size distribution on the properties of blended cements incorporating GGBFS and natural pozzolan (NP)," Powder Technology, vol. 177, no. 3, pp. 140-147, 2007.

[33] Technical sheet, GROUPE GICA industry group cements Algeria, Centre for Study and Technology Services Industry Building Materials C.E.T.I.M, Boumerdès, Algeria, 2013.

[34] R. H. Bogue, Chemistry of Portland Cement, Reinhold Publishing Corporation, New York, NY, USA, 2nd edition, 1955.

[35] European standard is issued by AFNOR (French Association of Standardization), standard CEN certified EN 196-1, ISO Standard Sand, according to ISO 679, 2009.

[36] N. F. Afnor, "(EN196-1) Methods of testing cement-part 1, determination of strength," April 2006.

[37] Y. Lo and H. M. Lee, "Curing effects on carbonation of concrete using a phenolphthalein indicator and Fourier-transform infrared spectroscopy," Building and Environment, vol. 37, no. 5, pp. 507-514, 2002.

[38] A. Darquennes, Behavior young age of concretes containing slag cement blast furnace condition of free and restricted deformation [Ph.D. thesis], Free University of Bruxelle, Brussels, Belgium, 2009.

[39] T. Gehlen and Y. Thomas, Formulation of environmental-based concrete materials efficient non-renewable resources [M.S. thesis], Free University of Bruxelle, Brussels, Belgium, 2009.

[40] K. Meinhard and R. Lackner, "Multi-phase hydration model for prediction of hydration-heat release of blended cements," Cement and Concrete Research, vol. 38, no. 6, pp. 794-802, 2008.

[41] J. Ollivier and A. Vichot, The Durability of Concrete-Scientific Basis for the Formulation of Durable Concrete in Their Environment, Presses the National School of Bridges and Roads, 2008.

[42] J. Baron, R. Gagne, and J. P. Ollivier, "Striving for durability in the concrete, bases and data for their formulation," in Collection ATHIL, pp. 307-363, Eyrolles, 1996. 
[43] R. G. Patel, D. C. Killoh, L. J. Parrott, and W. A. Gutteridge, "Influence of curing at different relative humidities upon compound reactions and porosity in Portland cement paste," Materials and Structures, vol. 21, no. 3, pp. 192-197, 1988.

[44] C. Ewertson and P. E. Petersson, "The influence of curing conditions on the permeability and durability of concrete. Results from a field exposure test," Cement and Concrete Research, vol. 23, no. 3, pp. 683-692, 1993.

[45] M. M. Y. Delmi, Study of hydration and carbonation water exchange coupling in mortars and concretes [Ph.D. thesis], University of Rochelle, 2004.

[46] S. Assie, Durability of self-compacting concrete [Ph.D. thesis], INSA Toulouse, Toulouse, France, 2004.

[47] Th. A. Bier, "Influence of type of cement and curing on carbonation progress and pore structure of hydrated cement pastes," MRS Proceedings, vol. 85, 18 pages, 1986.

[48] G. Sickert, "Extended modelling for the advance of carbonation in concrete," Concrete \& Prefabrication Technology, vol. 63, no. 12, pp. 74-88, 1997.

[49] S. Boualleg, P. Clastres, and M. Bencheikh, "Influence of the cure wet on mechanical and physical chemical mortar," in Processing and Properties of Advanced Ceramics and Composites VI: Ceramic Transactions, vol. 249, pp. 225-233, The American Ceramic Society, 2014.

[50] E. Rozière, A. Loukili, and F. Cussigh, "A performance based approach for durability of concrete exposed to carbonation," Construction and Building Materials, vol. 23, no. 1, pp. 190-199, 2009.

[51] C. Vernet, Chemical Stability of Hydrates-Defense Mechanism of Concrete against Chemical Attacks, the Durability of Concrete, Presses of l'ENPC, 1992.

[52] Th. A. Bier, "Influence of type of cement and curing on carbonation progress and pore structure of hydrated cement pastes," Materials Research Society Symposium, vol. 85, pp. 123$134,1987$.

[53] I. Medgyesi, "Control of reinforcement corrosion in reinforced concrete structures," Bulletin de Liaison des Laboratoires des Ponts et Chaussées, pp. 29-38, 1988.

[54] K. Garbev, Structure, properties and quantitative Rietveld analysis of calcium silicate hydrates (CSH Phases) crystallised under hydrothermal conditions [Ph.D. thesis], Institute for Technical Chemistry of the Faculty of Chemistry and Geosciences of the Ruprecht-Karls-Universitat, Hiedelberg, Germany, June 2004.

[55] H. F. W. Taylor, Cement Chemistry, Thomas Telford, London, UK, 2nd edition, 1998.

[56] S. C. Mojumdar and I. Janotka, "Thermophysical properties of blends from Portland and sulfoaluminate-belite cements," Acta Physica Slovaca, vol. 52, no. 5, pp. 435-446, 2002.

[57] I. G. Richardson, "Tobermorite/jennite- and tobermorite/calcium hydroxide-based models for the structure of C-S-H: applicability to hardened pastes of tricalcium silicate, $\beta$-dicalcium silicate, Portland cement, and blends of Portland cement with blast-furnace slag, metakaolin, or silica fume," Cement and Concrete Research, vol. 34, no. 9, pp. 1733-1777, 2004.

[58] J. I. Escalante, L. Y. Gómez, K. K. Johal, G. Mendoza, H. Mancha, and J. Méndez, "Reactivity of blast-furnace slag in Portland cement blends hydrated under different conditions," Cement and Concrete Research, vol. 31, no. 10, pp. 1403-1409, 2001.

[59] A. Bougara, C. Lynsdale, and N. B. Milestone, "Reactivity and performance of blastfurnace slags of differing origin," Cement and Concrete Composites, vol. 32, no. 4, pp. 319-324, 2010.
[60] L. Lam, Y. L. Wong, and C. S. Poon, "Degree of hydration and gel/space ratio of high-volume fly ash/cement systems," Cement and Concrete Research, vol. 30, no. 5, pp. 747-756, 2000.

[61] P. Barret and D. Bertrandie, "Fundamental hydration kinetic features of the major cement constituents, $\mathrm{Ca}_{3} \mathrm{SiO}_{5}$ and bCalSiO ${ }_{4}$, The Journal of Physical Chemistry, vol. 11/12, pp. 765$775,1983$.

[62] Y. Akli, Carbonation of concretes with high substitution rates of cement by mineral additions [Ph.D. thesis], Civil Engineering, Rochelle, Ill, USA, 2011. 

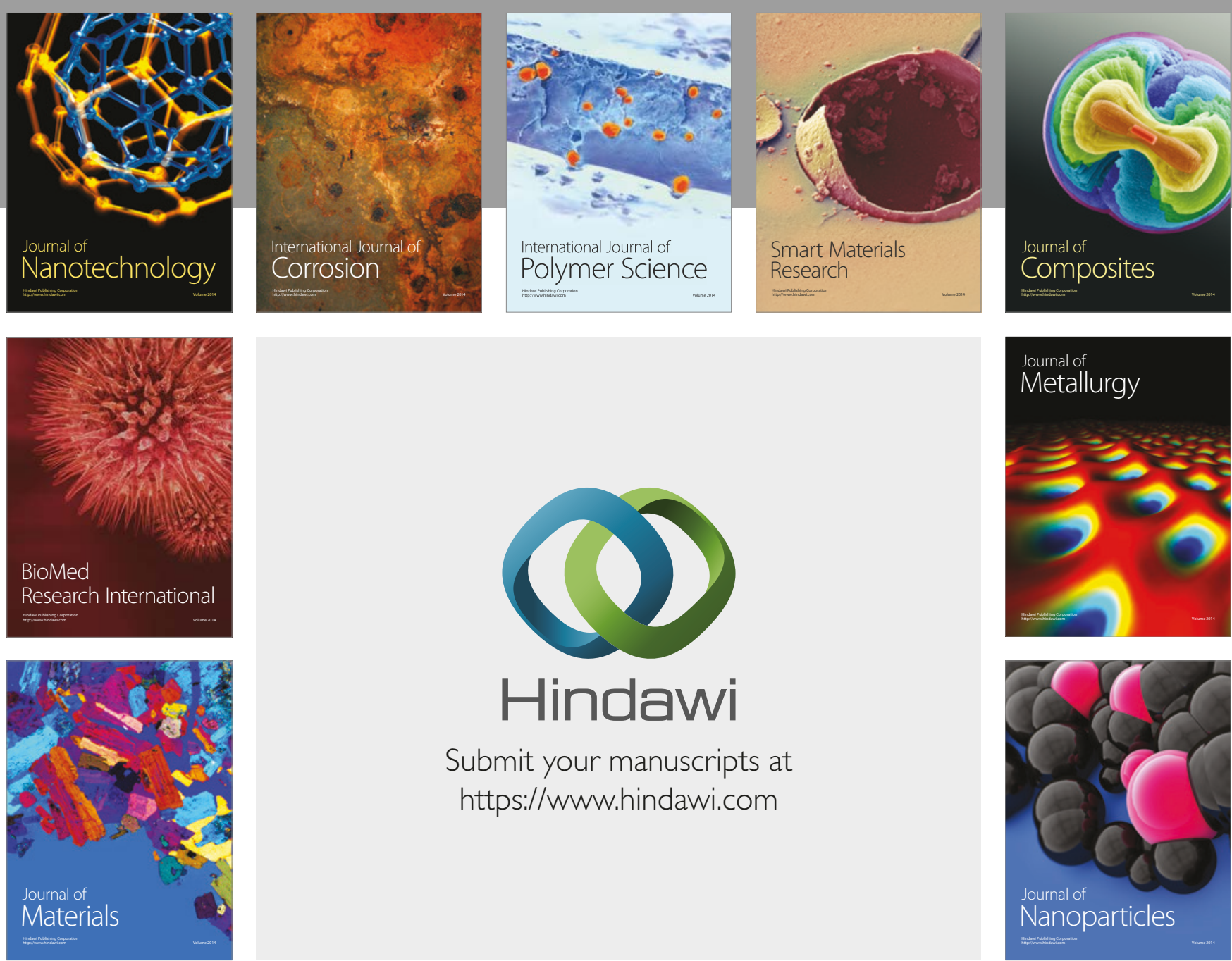

\section{Hindawi}

Submit your manuscripts at

https://www.hindawi.com
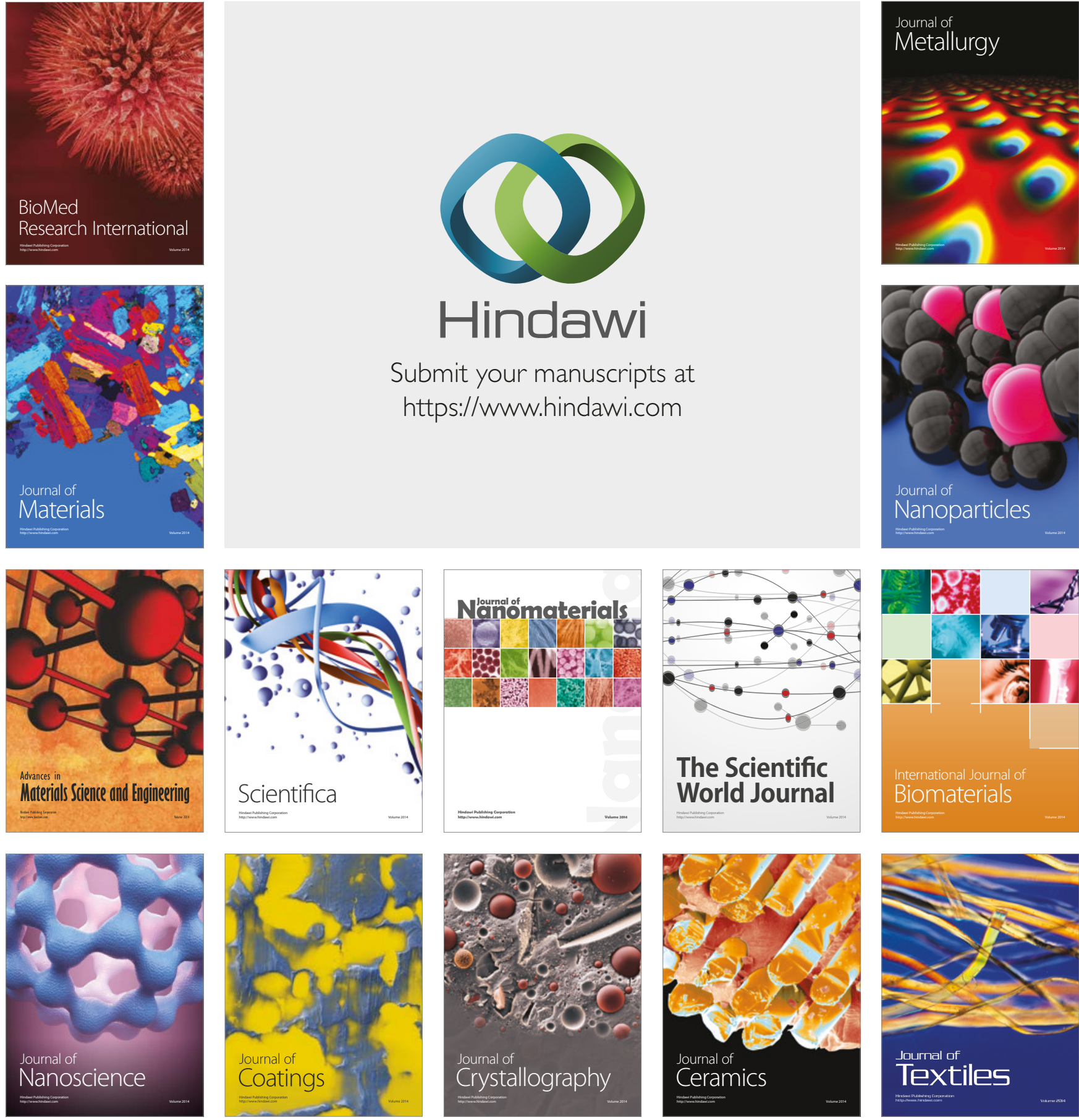

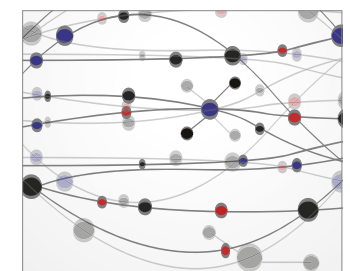

The Scientific World Journal
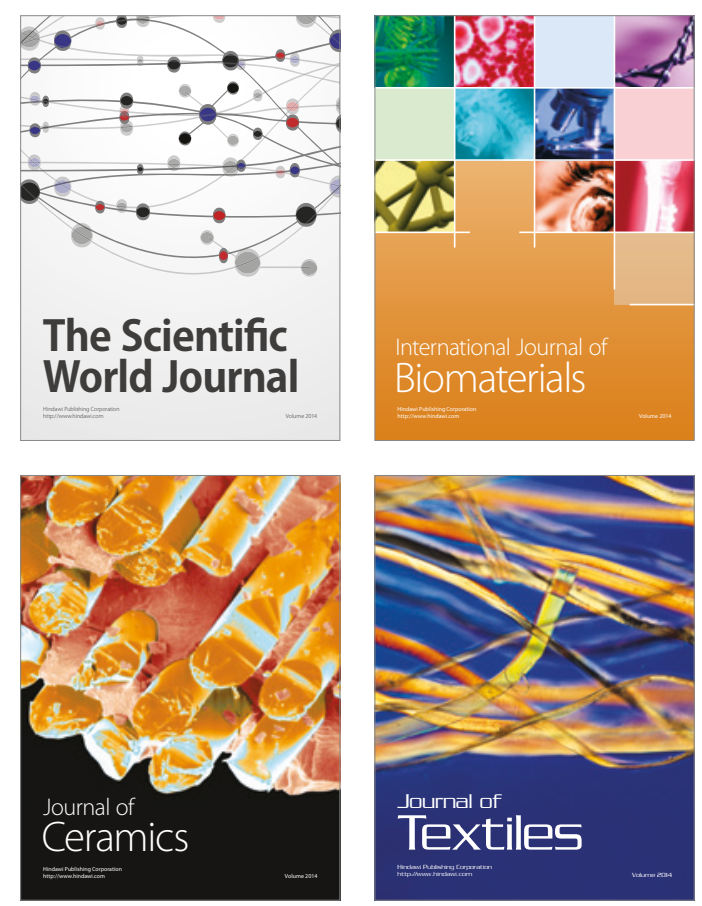